\title{
Padrões cefalométricos de Ricketts aplicados a indivíduos brasileiros com oclusão excelente
}

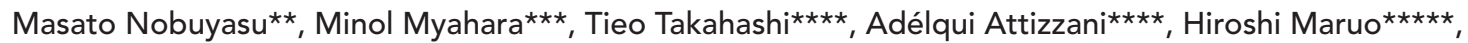 \\ Walter Rino ${ }^{\star \star \star \star \star}$, André Masato Nobuyasu ${ }^{\star \star \star \star \star \star}$, Sebastião Marcos Ribeiro de Carvalho ${ }^{\star \star \star \star \star \star \star ~}$
}

\section{Resumo}

Objetivo: avaliar cefalometricamente os 33 fatores cefalométricos, em norma lateral, dos 6 campos da análise de Ricketts em brasileiros e compará-los aos padrões cefalométricos de americanos. Metodologia: foram avaliados75 indivíduos brasileiros leucodermas, com idade variando entre 12 e 15 anos, considerados de melhor estética, equilíbrio, harmonia facial e, principalmente, portadores de oclusão dentária excelente, selecionados em uma triagem de 14.000 escolares de $1^{\circ} \mathrm{e}$ $2^{\circ}$ grau da região de Marília, Assis e Ourinhos/SP. Todos os 33 fatores das medidas cefalométricas dos 75 indivíduos foram comparados com os resultados obtidos por Ricketts em uma amostra de leucodermas americanos e submetidos a tratamento estatístico. Resultados e Conclusões: foi possivel concluir que 1) em nível esquelético, a maxila teve um comportamento dentro dos padrões preconizados pelo autor e a mandíbula teve uma tendência ao crescimento mais horizontal, tanto no seu corpo como no seu ramo; 2) a nível dentário, os incisivos inferiores se posicionaram mais anteriormente e com inclinação maior, o trespasse horizontal, vertical e a extrusão dos incisivos inferiores também estavam sensivelmente aumentados, provavelmente pela tendência ao crescimento horizontal da mandíbula; 3) o lábio inferior, em relação ao plano estético "E" de Ricketts, teve um posicionamento mais anterior em comparação ao padrão preconizado pelo autor; 4) os desvios clínicos na maioria dos fatores foram bem maiores nos brasileiros, em relação aos americanos, provavelmente devido à maior miscigenação nos leucodermas brasileiros.

Palavras-chave: Cefalometria. Análise de Ricketts. Padrões em brasileiros.

\section{INTRODUÇÃO}

A evolução da Ortodontia, ao longo do tempo da história e em função da diversificação de filosofias, técnicas e mecânicas ortodônticas utilizadas, têm contribuído para restabelecer no paciente o equilibrio oclusal e estética facial.

Para tanto, a cefalometria radiográfica tem for- necido muitos elementos aos ortodontistas em seu campo de trabalho, seja na pesquisa ou na prática clínica, dando-lhes informações a respeito da oclusão, da relação de bases ósseas da maxila e mandíbula - em sentido longitudinal - e da relação do posicionamento dos dentes. A cefalometria constitui um dos elementos auxiliares mais importan-

* Resumo da Dissertação de Mestrado apresentada à Faculdade de Ciências Odontológicas, da Universidade de Marilia, para obtenção do grau de Mestre em Odontologia, área de concentração Ortodontia.

** Mestre em Ortodontia pela Faculdade de Ciências Odontológicas de Marília - UNIMAR, Marília/SP. Professor coordenador do curso de especialização em Ortodontia e Ortopedia Facial da Universidade do Oeste Paulista - UNOESTE. Presidente Prudente/SP.

Orientador da dissertação e Professor Doutor do curso de pós-graduação em Ortodontia da Faculdade de Ciências Odontológicas - UNIMAR Marília/SP.

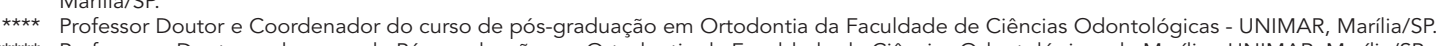

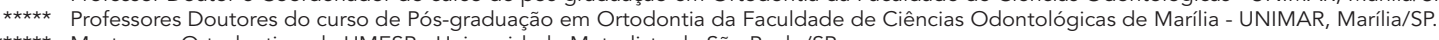

****** Mestre em Ortodontia pela UMESP - Universidade Metodista de São Paulo/SP.

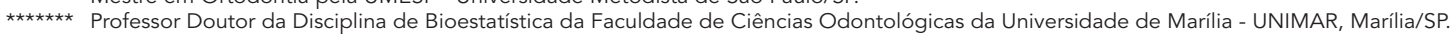


tes no diagnóstico e planejamento do tratamento ortodôntico, uma vez que a análise cefalométrica do conjunto dentofacial não está condicionada à classificação de Angle.

Embora o diagnóstico, o planejamento e o prognóstico dos casos em Ortodontia estejam ligados aos conceitos pessoais do ortodontista, as pesquisas cefalométrico-radiográficas na determinação de padrões dento-esquelético-faciais de normalidade trouxeram muitos benefícios a essa especialidade, cuja preocupação sempre presente, ao se elaborar um diagnóstico e plano de tratamento, é a meta cefalométrica a ser atingida. Para isso, é imprescindivel um correto estudo cefalométrico. No entanto, os fatores como idade, gênero e, especialmente, as diferenças étnicas poderão resultar em uma avaliação incorreta dos padrões cefalométricos estudados, se for usada uma análise cefalométrica como fonte de medidas definitivas e invariáveis para todos os pacientes.

$\mathrm{Na}$ literatura existem excelentes estudos de padrões cefalométricos, como os de Araújo $^{3}$, Interland ${ }^{15}$, Civolani ${ }^{6}$, Matos $^{20}$ e Rino ${ }^{36}$, entre outros, sendo que nenhum deles verificou em brasileiros leucodermas os seis campos e os trinta e três fatores estudados por Ricketts.

O presente estudo não tem a pretensão de lançar mais uma análise, mas simplesmente o objetivo de observar os padrões cefalométricos existentes na análise de Ricketts, pois há limitações do seu emprego em indivíduos brasileiros, uma vez que estão baseados em características faciais diferentes.

Desta forma, visando um conhecimento maior dos padrões de normalidade dos aspectos cefalométricos dentofaciais, julgamos válido realizar o presente estudo e verificar os padrões de análise de Ricketts, numa casuística de 75 indivíduos brasileiros na faixa etária de 12 a 15 anos, do gênero masculino e feminino, leucodermas, sem tratamento ortodôntico, portadores de "oclusão excelente", para facilitar o diagnóstico e a planificação do tratamento ortodôntico em brasileiros.

\section{REVISÃO DA LITERATURA}

Desde Pacini ${ }^{21}$, os estudos de cefalometria têm auxiliado na avaliação das telerradiografias em norma lateral que, com o uso do cefalostato, pode ser repetida, eliminando as limitações que eram impostas pelos primeiros métodos, como preceitaram Broadbent ${ }^{5}$ e Hofrath ${ }^{14}$.

Tweed ${ }^{40}$ afirmou que a oclusão normal, em seu sentido mais amplo, seria impossivel de ser conseguida sem um padrão facial. Estabeleceu parâmetros, utilizando o triângulo diagnóstico, e mostrou que um FMA de $35^{\circ}$ apresenta um prognóstico desfavorável.

Downs ${ }^{9}$, visando estabelecer padrões de normalidades facial e dentária dentre as medidas de avaliação do padrão esquelético, observou que a relação do incisivo inferior com a linha AP apresentou valor médio de $2,7 \mathrm{~mm}$ e desvio padrão de $1,80 \mathrm{~mm}$, com valor máximo de $5 \mathrm{~mm}$ e minímo de $-1 \mathrm{~mm}$.

Schaeffer ${ }^{37}$, estudando várias medidas em radiografias cefalométricas durante o crescimento, estabeleceu o valor médio do ângulo interincisivos: $139^{\circ}$ aos 7 anos; $130,27^{\circ}$ aos 8 anos e $129,17^{\circ}$ aos 9 anos.

Downs ${ }^{9}$, avaliando indivíduos na faixa etária de 12 a 17 anos com oclusão clinicamente excelente, encontrou para o ângulo facial um valor máximo de $95^{\circ}$ e mínimo de $82^{\circ}$, com média de $87,8^{\circ}$; e de $135,4^{\circ}$ para o ângulo interincisivos, com desvio padrão de $5,76^{\circ}$.

Ricketts $^{23}$ analisou 50 casos tratados de Classe II de Angle e verificou que o incisivo inferior estava posicionado $1 \mathrm{~mm}$ à frente do plano A-Po com uma inclinação de $22^{\circ}$ e o ângulo interincisivos de $130^{\circ}$.

Ricketts $^{24,25}$ avaliou 1.000 casos consecutivos, tratados em sua clínica, para identificar os problemas mais comuns em Ortodontia: 1) planos de referências dentárias: linha do plano A-Po - denominado "plano dentário" por conectar as estruturas mais anteriores dos ossos basais (maxilares) - e plano oclusal - delineado da cúspide dos primeiros pré-molares à cúspide distal dos primeiros molares inferiores; 2) incisivo inferior: localização e posição. Quando a linha A-Po for empregada como 
um plano de referência, o incisivo inferior pode ser ajustado para se posicionar dentro de um desvio clínico da variação natural, podendo estar até $1 \mathrm{~mm}$ à frente ou atrás do plano $\mathrm{A}-\mathrm{Po}$. O valor médio dos 1.000 casos ortodônticos foi de $2,5 \mathrm{~mm}$, com desvio clínico considerado satisfatório de $-3,5 \mathrm{~mm}$ a $3,5 \mathrm{~mm}$. Ainda determinou o ângulo facial como indicador de profundidade facial, estabelecendo uma média de $85,4^{\circ}$. Esta medida, no início do tratamento, foi de $86,1^{\circ}$ na Classe I; $84^{\circ}$ na Classe II; $85^{\circ}$ nos casos tratados com ancoragem extrabucal; $84,7^{\circ}$ com uso de força inter-maxilar e $86^{\circ}$ nos casos de tratamentos combinados. Nos casos sem tratamento, o ângulo facial aumentou entre $0,8^{\circ}$ e $1,2^{\circ}$ no período de 30 meses, ou seja $0,35^{\circ}$ ao ano. Em relação ao ângulo do plano mandibular, estabeleceu um valor médio de $25,6^{\circ}$, sendo $25,7^{\circ}$ na Classe I; $27,7^{\circ}$ na Classe II; $25,6^{\circ}$ nos casos tratados com ancoragem extrabucal e $24,1^{\circ}$ naqueles com uso de força inter-maxilar, sendo esse ângulo mais empregado como referência de crescimento. Determinou o ângulo facial como um indicador de profundidade, obtendo uma média de $85,14^{\circ}$. No início do tratamento, utilizando o pório anatômico, a média foi de $86,1^{\circ}$, sendo $84^{\circ}$ na Classe I; $85^{\circ}$ na Classe II, no início do tratamento; $84,7^{\circ}$ nos casos tratados com ancoragem extrabucal; $84,7^{\circ}$ com uso de força inter-maxilar e $86^{\circ}$ nos casos de tratamento combinado, mostrando a grande variabilidade em função do tipo de tratamento.

Gresham ${ }^{10}$ comparou as medidas do ângulo interincisivos de americanos e neozelandeses e obteve um valor médio, respectivamente de $125,88^{\circ}$ com desvio clínico de $5,84^{\circ}$ e $131,04^{\circ}$ com desvio clínico de $6,23^{\circ}$.

Ricketts $^{27}$ definiu como objetivo para o posicionamento do lábio inferior no tratamento de pacientes na puberdade, na faixa de 12 a 14 anos uma média de $2 \mathrm{~mm} \pm 3 \mathrm{~mm}$ para o lábio inferior atrás do plano $\mathrm{E}$, o que permitia uma variação com o tratamento ortodôntico de $-5 \mathrm{~mm}$ a $1 \mathrm{~mm}$, enquanto em adultos foi de $4 \mathrm{~mm} \pm 3 \mathrm{~mm}$.

Hirsch et al. ${ }^{13}$ estudaram 30 indivíduos leu- codermas, americanos, na faixa etária de 8 anos e 6 meses, de ambos os gêneros, sem evidência de má oclusão, para estabelecer a média do ângulo FNP (medida angular inferior formada pela interseção do plano horizontal de Frankfurt e a linha násio-pogônio). $\mathrm{O}$ valor médio encontrado foi de $84,85^{\circ} \pm 5,01^{\circ}$ para o gênero feminino e $83,6^{\circ} \pm 4,48^{\circ}$ para o masculino.

Para Ricketts ${ }^{28}$ existiam 4 métodos principais para se chegar a um conceito de normalidade. A palavra normal corresponderia a um padrão aceito ou a um padrão de correção ideal, que aciona uma imagem mental, primeiramente. Um segundo método, objetivado nesse estudo, foi o acúmulo e processamento de uma amostra, com ausência de patologia conhecida. Um terceiro método foi o de fechar um campo, a fim de reconhecer as condições patológicas de qualquer enfermidade, considerando normal como qualquer coisa que se situe na ausência de doença ou que não seja patológica. Um quarto método foi de compreensão de princípios gerais ou leis biológicas de comportamento. Concluindo que essas normas norteiam o profissional na execução do tratamento.

Ricketts $^{29}$ definiu a posição do mento no espaço, usando referencial basal e cranial; orientou a maxila (ponto A) no perfil, em harmonia ideal para o indivíduo e elaborou um novo plano A-pogônio, que serviu de parâmetro para se posicionar a arcada. Ainda considerou, teoricamente, que, quanto mais reduzido o ponto A mais lingualmente estaria relacionado ao incisivo inferior e definiu os valores para os incisivos inferiores como sendo de $1 \mathrm{~mm} \pm 1,5 \mathrm{~mm}$.

Cox e Van der Linden ${ }^{7}$ destacaram, dentre as medidas dentoesqueléticas, o valor médio do ângulo interincisivos com excelente harmonia facial $\left(139,60^{\circ}\right)$ e com pobre harmonia facial $\left(131,2^{\circ}\right)$.

Kowalski e Walker ${ }^{16}$, em uma amostra de 1.104 indivíduos com oclusão normal, numa faixa etária de 6 a 26 anos, encontraram um valor de $129^{\circ}$ para o ângulo interincisivos.

Ricketts $^{30}$ estudou a posição dos primeiros 
molares superiores em várias idades e descobriu que a distal do primeiro molar superior à linha Pt.V (perpendicular ao plano de Frankfurt) exibia um valor médio, em indivíduos em crescimento, equivalente à idade do indivíduo somada a $3 \mathrm{~mm}$. Outro fator estudado pelo autor foi o eixo facial, formado a partir do ponto da margem inferior do forame redondo até o gnátio, medido quando este cruza o plano básio-násio, formando um ângulo de $90^{\circ} \pm 3^{\circ}$, que não se alterou com a idade.

Ricketts $^{31}$ avaliou 40 indivíduos sem tratamento ortodôntico e resumiu os dados obtidos em cinco áreas de consideração: 1) significância clínica; 2) significância anatômica; 3) precisão da medida; 4) aplicação na descrição e 5) aplicação no prognóstico de crescimento.

Civolani ${ }^{6}$, analisando e comparando seus resultados com os padrões cefalométricos de Tweed, Steiner, Wylie e Downs, em 40 radiografias cefalométricas, em norma lateral, de indivíduos da cidade de Piracicaba/SP, na faixa etária de 11 a 14 anos, do gênero masculino e feminino, com oclusão dentária "normal", concluiu que havia diferenças estatisticamente significantes entre os valores considerados padrões e os da amostra estudada, para as seguintes variáveis: ângulos FMA, FMIA, IMPA e ANB da análise de Tweed; ângulos SNB, ANB, SN.GoGn, SN.PIO, 1.NB e medidas lineares 1-NA, 1-NB e SE da análise de Steiner; medidas lineares correspondentes ao comprimento da maxila, posição ântero-posterior do primeiro molar superior e comprimento da mandíbula da análise de Wylie e ângulo HF.NPg, NA.Pg, eixo Y, PM.HF, PIO.HF e medida linear 1-Apg da análise de Downs.

Martins $^{19}$, avaliando 85 indivíduos com oclusão normal, observou um valor médio de $128,14^{\circ}$ e desvio clínico de $6,78^{\circ}$ para o ângulo interincisivos.

Matos $^{20}$, observando 48 indivíduos sem tratamento ortodôntico e com a melhor estética, concluiu que: 1) o padrão esquelético de sua amostra era semelhante ao dos americanos e 2) os padrões dentários apresentaram-se mais protrusos que nos americanos.

Ramanzini'22, estudando 80 indivíduos, de ambos os gêneros, na faixa etária entre 11 e 15 anos, sendo 40 com oclusão normal e 40 com Classe II divisão 1 , verificou que o valor médio do ângulo interincisivos foi de $127,53^{\circ}$, para o gênero masculino e $124,68^{\circ}$ para o feminino.

Ricketts $^{32}$, realizando uma retrospectiva de cefalometria radiográfica em crescimento das últimas 5 décadas e dentre os fatores da análise cefalométrica em norma lateral em nível esquelético, observou o valor médio de $122^{\circ}$ para o ângulo interincisivos aos 3 anos; $124^{\circ}$ aos 8 anos; $126^{\circ}$ aos 13 anos; $128^{\circ}$ aos 18 anos para homens e $130^{\circ}$ aos 23 anos para homens. A medida incisivo inferior a APo foi de $1 \mathrm{~mm} \pm 2 \mathrm{~mm}$, com uma variação de $\pm 2,5 \mathrm{~mm}$ à frente ou atrás da linha APo, não se alterando com a idade. Quanto à posição do molar superior para Pt.V, que avalia o espaço disponível para os molares superiores, costumavase usar o padrão de $3 \mathrm{~mm}$. Entretanto, as variações com a idade foram as seguintes: $6 \mathrm{~mm}$ aos 3 anos; $-9 \mathrm{~mm}$ aos 6 anos; $12 \mathrm{~mm}$ aos 9 anos; $15 \mathrm{~mm}$ aos 12 anos; $18 \mathrm{~mm}$ aos 15 anos; $21 \mathrm{~mm}$ aos 18 anos para homens; $24 \mathrm{~mm}$ aos 21 anos e $27 \mathrm{~mm}$ aos 24 anos. O eixo facial construído entre a conexão do gnátio e o ponto $\mathrm{Pt}$, ao cruzar com a linha básio-násio medida em CC, apresentou um valor de $90^{\circ} \mathrm{com}$ desvio clínico de $\pm 3^{\circ}$. Foi um dos fatores utilizados para determinação do padrão facial de crescimento.

Bishara ${ }^{4}$ fez um estudo longitudinal de uma amostra de 35 indivíduos leucodermas norte americanos, sendo 20 do gênero masculino e 15 do feminino, todos com oclusão aceitável, sem tratamento ortodôntico, na faixa etária de 5 a 12 anos para gênero feminino e 5 a 10 anos para o masculino. Dentre as medidas obtidas, o ângulo interincisivos foi de $131^{\circ} \pm 7,3^{\circ}$.

Ricketts et al. ${ }^{33}$ descreveram a Análise Sumária ou Análise dos 11 fatores, com medidas angulares e lineares estudadas em indivíduos caucasianos ame- 
ricanos com oclusão normal, na idade de 9 anos: MENTO - 1) eixo facial $=90^{\circ} \pm 3^{\circ}$ - não se alterava com a idade; 2) ângulo facial $=87^{\circ} \pm 3^{\circ}$ - aumentava $1^{\circ}$ a cada 3 anos; 3 ) ângulo do plano mandibular $=26^{\circ} \pm 4^{\circ}$ - diminuía $1^{\circ}$ a cada 3 anos; 4) altura facial inferior (altura da dentição) $=47^{\circ} \pm 4^{\circ}$ - não se alterava com a idade; 5$)$ arco mandibular = $26^{\circ} \pm 4^{\circ}$ - aumentava $0,5^{\circ}$ a cada ano. MAXILA 6) convexidade Ponto $A=2 \mathrm{~mm} \pm 2 \mathrm{~mm}$ - diminuía $1 \mathrm{~mm}$ a cada 3 anos. DENTES - 7) incisivo inferior ao $\mathrm{APo}=1 \mathrm{~mm} \pm 2 \mathrm{~mm}$ - não se alterava com a idade; 8) molar superior ao Pt.V $=12 \mathrm{~mm} \pm 2 \mathrm{~mm}$ - aumentava $1 \mathrm{~mm}$ por ano (em crescimento); 9) inclinação do incisivo central inferior $=22^{\circ} \pm 4^{\circ}$ - não se alterava com a idade. PERFIL - 10) lábio inferior ao plano $\mathrm{E}=-2 \mathrm{~mm} \pm 2 \mathrm{~mm}-$ menos protruso $0,2 \mathrm{~mm}$ por ano. Com medidas angulares e lineares de indivíduos com oclusão normal, através da média dos cinco primeiros fatores, determinaram os três padrões faciais baseados na quantidade de crescimento vertical (VERT): dolicofacial (crescimento vertical), mesofacial (crescimento "normal") e braquifacial (crescimento horizontal). Classificando o valor de VERT 0 (zero) como sendo do tipo mesofacial, valores negativos como dolicofacial (-0,5 dólico suave e a partir de -2 dólico severo) e valores positivos como braquifacial $(0,5$ braquifacial e a partir de 1 braquifacial severo). Ao descreverem a análise sumária dos fatores em indivíduos caucasianos americanos, com 9 anos de idade e oclusão normal, observaram que a distância do incisivo inferior a APo não se alterava com a idade e encontraram a média de $1 \mathrm{~mm} \pm 2 \mathrm{~mm}$, com uma inclinação de $22^{\circ} \pm 4^{\circ}$, enquanto a distância do molar superior a Pt.V encontrada foi de $12 \mathrm{~mm} \pm 2 \mathrm{~mm}$, aumentando $1 \mathrm{~mm}$ por ano (em crescimento). Afirmaram que a posição do lábio era muito importante para a estética facial. Ao avaliar o plano palatal observaram uma grande variabilidade, lembrando-se que um objetivo no tratamento ortodôntico é posicionar este plano paralelo ao plano horizontal de Frankfurt.
A medida ideal foi de $0^{\circ}$ ou $180^{\circ}$, com desvio clínico de $\pm 3^{\circ}$. Após acurados estudos, propuseram o que chamaram de Análise Sumária ou Análise dos 10 fatores.

Almeida e Vigorito ${ }^{1}$, em estudo comparativo entre padrões cefalométricos, avaliaram 57 indivíduos de ambos os gêneros, com oclusão normal, e observaram a média de $129,3^{\circ} \pm 9,41^{\circ}$ para o ângulo interincisivos.

Siqueira ${ }^{38}$ observou que o ângulo interincisivos mostrava-se variável: $129,2^{\circ}$ aos 7 anos; $126,4^{\circ}$ aos 8 anos; $127,8^{\circ}$ aos 9 anos e $129,05^{\circ}$ aos 10 anos.

Rino Neto $^{35}$ estudou 30 indivíduos leucodermas, 13 do gênero masculino e 17 do feminino, brasileiros com oclusão clinicamente excelente, na faixa etária de 7 a 9 anos, e encontrou um padrão dentário de $122,45^{\circ}$ para o ângulo interincisivos e de $86,5^{\circ} \pm 3,39^{\circ}$ para o ângulo facial.

Rino $^{36}$, estudando 90 telerradiografias de indivíduos leucodermas, brasileiros de ambos os gêneros, na faixa de 9 a 14 anos, encontrou valores médios que variaram em cada faixa etária estudada: $124,80^{\circ}$ aos 9 anos; $126,53^{\circ}$ aos 10 anos; $127,53^{\circ}$ aos 11 anos; $129,33^{\circ}$ aos 12 anos; $124,86^{\circ}$ aos 13 anos e $129,20^{\circ}$ aos 14 anos.

\section{PROPOSIÇÃO}

Avaliar cefalometricamente os 33 fatores cefalométricos, em norma lateral, dos 6 campos da análise de Ricketts em brasileiros e compará-los aos padrões cefalométricos de americanos.

\section{MATERIAL E MÉTODOS Material}

Foram utilizadas 75 telerradiografias cefalométricas em norma lateral, de indivíduos na faixa etária de 12 a 15 anos, leucodermas, brasileiros, sendo 40 do gênero feminino e 35 do masculino, obtidas entre 14.000 estudantes examinados, residentes na região de Marília, Assis e Ourinhos/SP.

A amostra estudada foi selecionada dentro das características próximas da oclusão clinicamente normal, descrita por Angle ${ }^{2}$ e Ricketts ${ }^{28,33}$. 


\section{Métodos}

$\mathrm{O}$ traçado das estruturas cefalométricas seguiu os critérios de Ricketts ${ }^{26,33}$, Langlade ${ }^{17}$ e Vion ${ }^{41}$.

A análise cefalométrica de Ricketts é composta de 33 fatores, divididos em seis campos:

\section{Campo I - problemas dentários (Relação oclu-} sal) (Fig.1)

\section{1) Relação molar}

Esta relação corresponde à distância entre as faces distais dos primeiros molares superior e inferior, medida no plano oclusal.

Normal clínico:

Classe I $=-3, \mathrm{~mm}$;

Classe II $=>0$;

Classe III $=<-6 \mathrm{~mm}$;

Desvio clínico: $\pm 3 \mathrm{~mm}$.

Interpretação: quando as grandezas forem positivas, indicam que o molar superior está em posição mesial ao inferior. Valores negativos indicam que o molar superior está em posição distal em relação ao inferior.

\section{2) Relação dos caninos}

Distância entre as cúspides do canino superior e inferior, medida no plano oclusal.

Normal clínico:

Classe I $=-2 \mathrm{~mm}$;

Classe II $=+1 \mathrm{~mm}$ ou mais;

Classe III $=<-5 \mathrm{~mm}$;

Desvio clínico: $\pm 3 \mathrm{~mm}$.

Interpretação: informa-nos sobre a chave do canino, se é de Classe I, II ou III.

\section{3) Trespasse horizontal (Sobressaliência)}

Distância entre a borda dos incisivos, superior e inferior.

Normal clínico: $2,5 \mathrm{~mm}$.

Desvio clínico: $\pm 2,5 \mathrm{~mm}$.

Interpretação: fornece a quantidade de trespasse entre os incisivos superiores e inferiores. Para uma avaliação completa, deve-se correlacionar com a inclinação e posição dos incisivos.

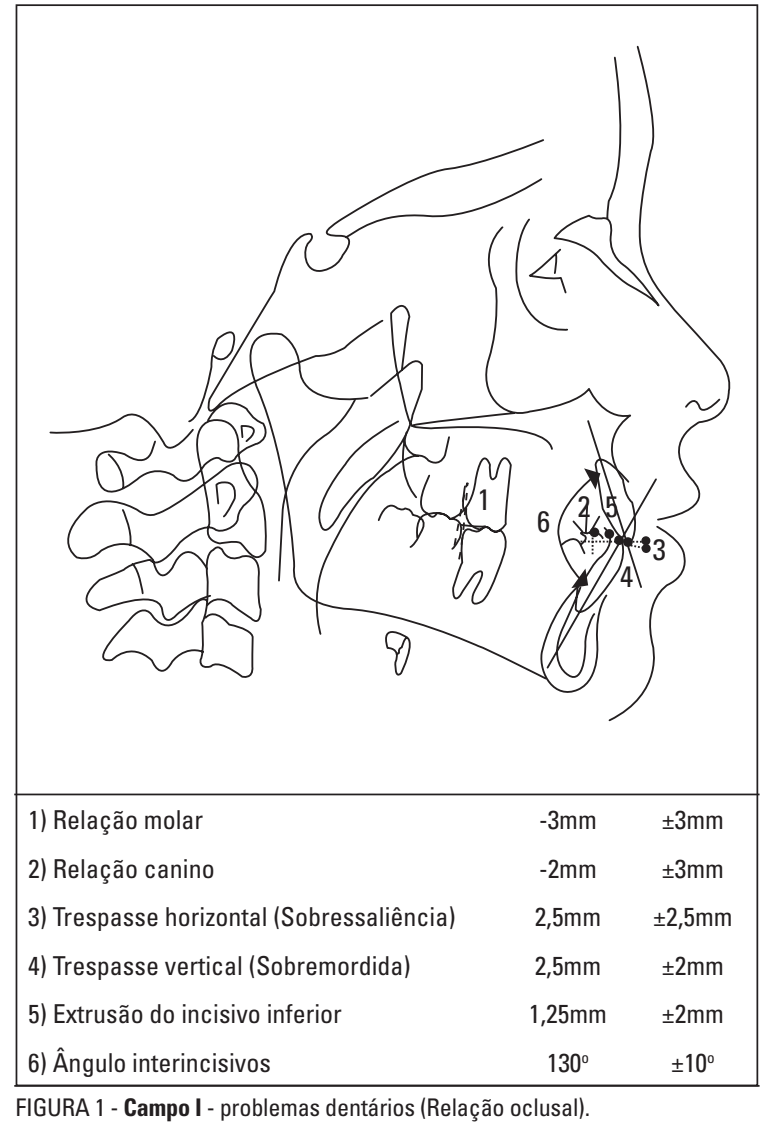

4) Trespasse vertical (Sobremordida)

Distância entre as bordas dos incisivos, superior e inferior, medida perpendicularmente ao plano oclusal.

Normal clínico: $2,5 \mathrm{~mm}$.

Desvio clínico: $\pm 2 \mathrm{~mm}$.

Interpretação: descreve a má oclusão no sentido anterior, por meio da dimensão vertical.

\section{5) Extrusão dos incisivos inferiores}

Distância entre a borda do incisivo inferior ao plano oclusal.

Normal clínico: $1,25 \mathrm{~mm}$.

Desvio clínico: $\pm 2 \mathrm{~mm}$.

Interpretação: informa se o trespasse vertical do incisivo se deve à sobreirrupção ou infrairrupção do incisivo inferior. 


\section{6) Ângulo interincisivos}

É o ângulo formado pelo longo eixo dos incisivos, superior e inferior.

Normal clínico: $130^{\circ}$.

Desvio clínico: $\pm 10^{\circ}$.

Interpretação: de 100 a $119^{\circ}$ é indicativo de biprotrusão, de 120 a $139^{\circ}$ é considerado normal e de 140 a $160^{\circ}$ tem-se uma birretrusão.

\section{Campo II - problemas esqueléticos (relação ma- xilo-mandibular) (Fig. 2)}

7) Convexidade do ponto "A"

Medida linear entre o ponto "A "e o plano facial.

Média: $2 \mathrm{~mm} \pm 2 \mathrm{~mm}$ aos 8 anos e 6 meses, diminuindo $0,2 \mathrm{~mm}$ a cada ano.

Interpretação: valores altos indicam padrão de Classe II esquelética. Quando o valor for negativo, é indicativo de Classe III esquelética.

\section{8) Altura facial inferior (Altura da dentição)}

Ângulo formado pelo plano Xi - Pm e pela linha Xi - ENA.

Média: $47^{\circ} \pm 4^{\circ}$.

Interpretação: divergência da cavidade bucal. Valores altos representam mordida aberta esquelética e valores baixos sobremordida. Este fator não se altera com a idade.

Campo III - problemas dentoesqueléticos (Fig. 3) 9) Posição do $1^{\circ}$ molar superior a PTV

Distância da vertical pterigóide até a face distal do primeiro molar superior.

Média: idade do paciente em anos, acrescido de $3 \mathrm{~mm} \pm 3 \mathrm{~mm}$.

Interpretação: informa se a má oclusão é devida à posição do molar superior ou inferior.

\section{0) Protrusão do incisivo inferior (1-APo)}

Medida linear que vai da borda do incisivo inferior até a linha APo.

Média: $1 \mathrm{~mm} \pm 2 \mathrm{~mm}$.

Interpretação: este fator determina uma posição estética e funcional para o incisivo inferior.

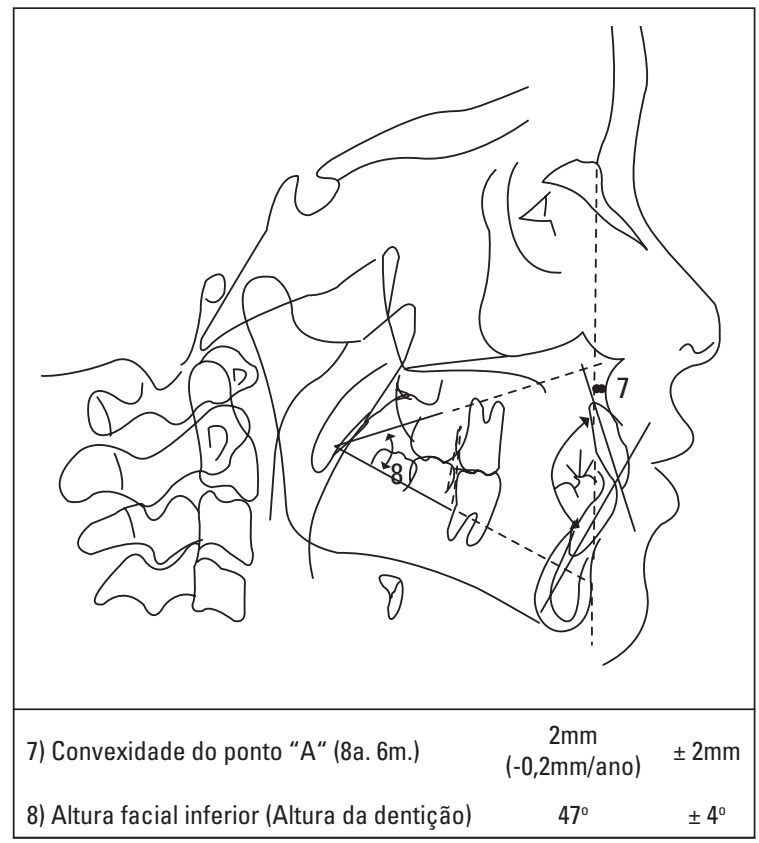

FIGURA 2 - Campo II - problemas esqueléticos (Relação maxilo-mandibular).

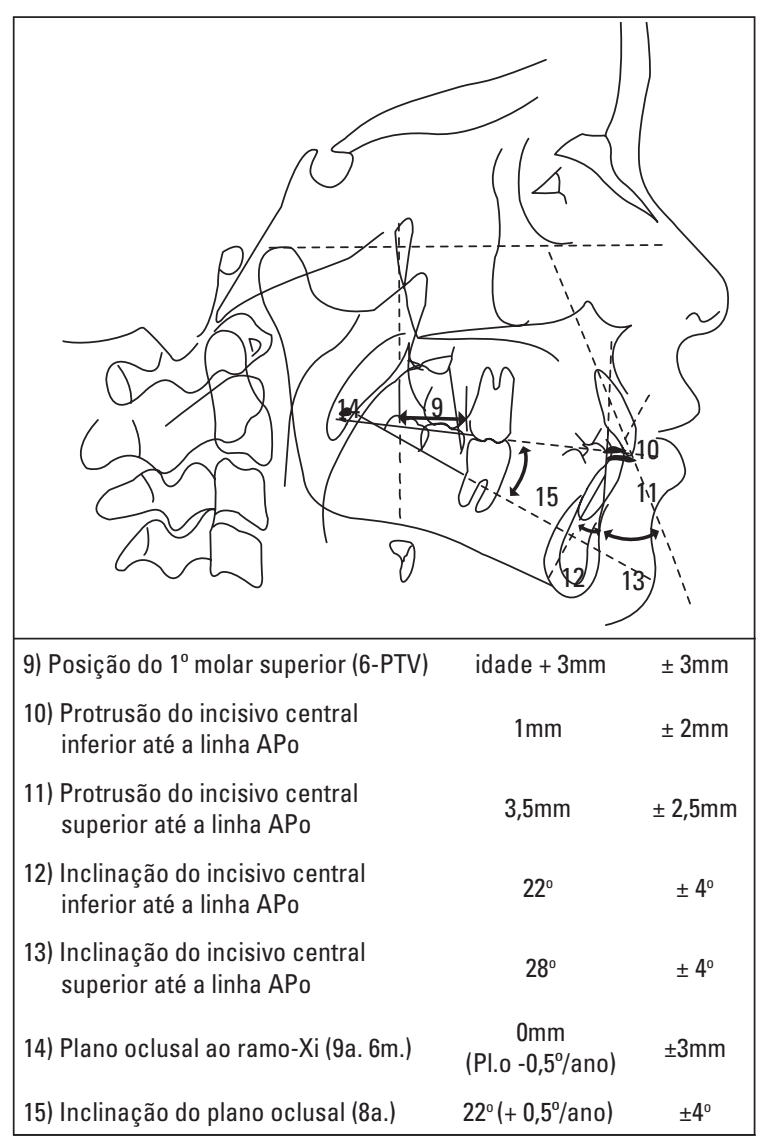

FIGURA 3 - Campo III - problemas dentoesqueléticos. 
11) Protrusão do incisivo superior até a linha APo Média: 3,5mm $\pm 2,5 \mathrm{~mm}$.

Interpretação: define a protrusão do incisivo superior com relação aos maxilares.

\section{2) Inclinação do incisivo central inferior (1. APo)}

Ângulo formado pelo longo eixo do incisivo inferior com a linha APo.

Média: $22^{\circ} \pm 4^{\circ}$.

Interpretação: este fator determina o grau de inclinação dos incisivos inferiores.

13) Inclinação do incisivo central superior (1.APo)

Ângulo formado através do longo eixo do incisivo superior com a linha APo.

Média: $28^{\circ} \pm 4^{\circ}$.

Interpretação: este fator determina o grau de inclinação dos incisivos superiores.

\section{4) Plano oclusal ao ramo (Xi)}

Distância entre o plano oclusal e o ponto Xi.

Média: $0 \mathrm{~mm} \pm 3 \mathrm{~mm}$ aos 9 anos e 6 meses.

Esta distância decresce $0,5 \mathrm{~mm}$ ao ano em relação ao ponto Xi.

Interpretação: grandezas positivas indicam que o plano oclusal está acima do ponto Xi, denotando Classe II, e Classe III se negativas.

\section{5) Inclinação do plano oclusal}

Ângulo formado pela intersecção do eixo do corpo (Xi-Pm) com o plano oclusal.

Média: $22^{\circ} \pm 4^{\circ}$ até a idade de 8 anos. Aumenta $0,5^{\circ}$ por ano.

Interpretação: situa o plano oclusal com referência à estrutura interna da mandíbula.

\section{Campo IV - problemas estéticos (Fig. 4) \\ 16) Posição labial}

Distância linear entre o ponto lábio inferior (Li) até o plano estético (E).

Média: $-2 \mathrm{~mm} \pm 2 \mathrm{~mm}$ até a idade de 8 anos 6 meses.

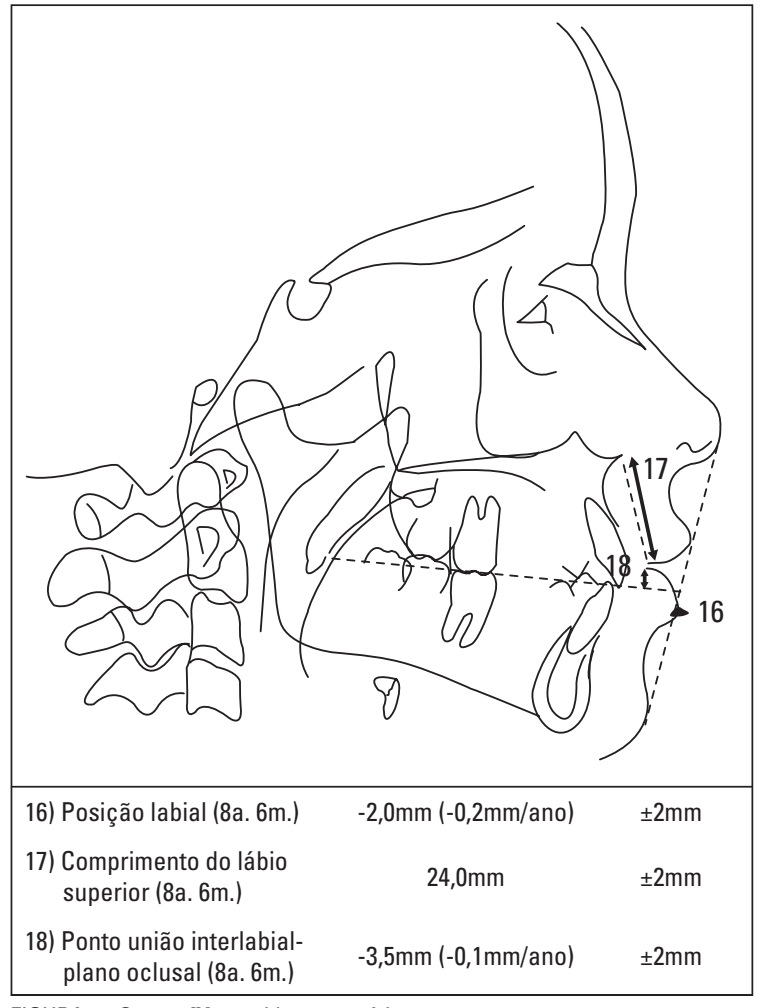

FIGURA 4 - Campo IV - problemas estéticos.

Diminui $0,2 \mathrm{~mm}$ por ano.

Interpretação: permite uma correlação do perfil labial com o restante do perfil facial.

\section{7) Comprimento do lábio superior}

Distância entre a espinha nasal anterior (ENA) e o estômio (Stm).

Média: $24 \mathrm{~mm} \pm 2 \mathrm{~mm}$ para 8 anos e 6 meses.

Interpretação: a análise do comprimento do lábio superior deve estar relacionada à avaliação do incisivo superior.

\section{8) Ponto união interlabial - plano oclusal}

Distância do ponto de união interlabial (Estômio - Stm) ao plano oclusal.

Média: $-3,5 m m \pm 2 m m$ aos 8 anos e 6 meses.

Esta distância decresce $0,1 \mathrm{~mm}$ ao ano em relação ao plano oclusal.

Interpretação: o plano oclusal deve ficar abaixo do ponto de união. 


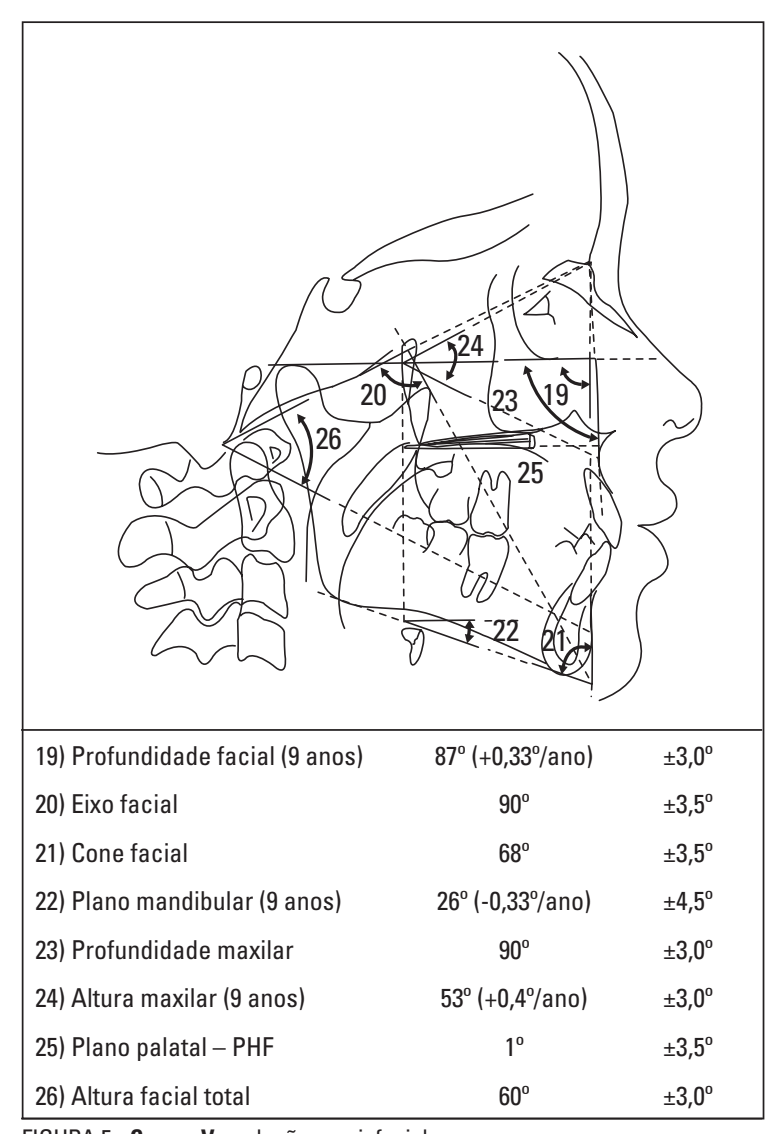

FIGURA 5 - Campo V - relação craniofacial.

\section{Campo V - relação craniofacial (Fig. 5)}

\section{9) Profundidade facial}

Ângulo póstero-inferior formado pela intersecção do plano facial com o plano de Frankfurt.

Média: $87^{\circ} \pm 3^{\circ}$ aos 9 anos. Aumenta $0,33^{\circ}$ por ano.

Interpretação: posiciona o mento no sentido horizontal. Determina se a Classe II ou Classe III é de natureza esquelética.

\section{0) Eixo facial}

É o ângulo formado através do plano básio-násio e o eixo facial.

Média: $90^{\circ} \pm 3,5^{\circ}$.

Interpretação: indica a direção de crescimento do mento e a posição dos molares. Expressa a relação entre a altura e a profundidade facial.

\section{1) Cone facial}

Ângulo medido na intersecção do plano facial com o plano mandibular.

Média: $68^{\circ} \pm 3,5^{\circ}$.

Interpretação: ângulos maiores, nos casos de Classe II, representam indivíduos braquifaciais com retrusão mandibular; ângulos menores, em Classe III, indivíduos dolicofaciais.

\section{2) Ângulo do plano mandibular}

Ângulo formado pelo plano de Frankfurt e o plano mandibular.

Média: $26^{\circ} \pm 4,5^{\circ}$ aos 9 anos. Diminui $0,33^{\circ}$ por ano.

Interpretação: parâmetro que permite uma avaliação vertical da mandíbula em relação ao plano de Frankfurt.

\section{3) Profundidade maxilar}

Ângulo formado pelo plano de Frankfurt com a linha $\mathrm{Na}-\mathrm{A}$.

Média: $90^{\circ} \pm 3^{\circ}$.

Interpretação: indica a posição horizontal (ântero-posterior) da maxila. Um padrão de Classe II esquelético, devido à maxila, apresenta valores superiores a $90^{\circ}$.

\section{4) Altura maxilar}

Ângulo formado pelas linhas CF-Na e CF-A.

Média: $53^{\circ} \pm 3^{\circ}$, aos 9 anos. Aumenta $0,4^{\circ}$ por ano.

Interpretação: indica a posição vertical da maxila.

A mordida aberta esquelética, devido à maxila, apresenta um valor diminuído deste ângulo.

\section{5) Plano palatino / plano horizontal de Frankfurt}

Ângulo formado pelo plano palatino e o plano de Frankfurt.

Média: $1^{\circ} \pm 3,5^{\circ}$.

Interpretação: ângulo aumentado indica que o palato está inclinado no sentido anti-horário, com mordida aberta esquelética devida à maxila. 


\section{6) Altura facial total}

Ângulo determinado pela intersecção do prolongamento do plano Xi-Pm com a linha Ba-Na.

Média: $60^{\circ} \pm 3^{\circ}$.

Interpretação: avaliação do comportamento do corpo mandibular com a base total do crânio.

\section{Campo VI - estruturas internas (Fig. 6)}

27) Deflexão craniana

Ângulo obtido pela intersecção do plano de Frankfurt com o plano básio-násio.

Média: $27^{\circ} \pm 3^{\circ}$.

Interpretação: um ângulo alto constitui um alerta para um padrão de crescimento excessivo da mandíbula (Classe III); por outro lado, um ângulo baixo apresenta tendência para um posicionamento posterior da mandíbula.

\section{8) Comprimento craniano anterior}

Distância entre o ponto CC e Násio.

Média: $55 \mathrm{~mm} \pm 2,5 \mathrm{~mm}$ até a idade de 8,5 anos.

Deve ser alterado de acordo com o tamanho da cabeça do paciente. Em média, aumenta $0,8 \mathrm{~mm}$ ao ano.

Interpretação: indica se o padrão de Classe II esquelética é devido ao alongamento da base craniana ou se a Classe III é devida à diminuição desta base.

\section{9) Altura facial posterior}

Distância entre os pontos CF e Go.

Média: $55 \mathrm{~mm} \pm 3,3 \mathrm{~mm}$ aos 8,5 anos. Deve ser alterada de acordo com o tamanho da cabeça. Em média, aumenta $0,8 \mathrm{~mm}$ ao ano.

Interpretação: determina a altura do ramo da mandíbula. É responsável pelo padrão vertical do ramo.

\section{0) Posição do ramo}

Ângulo formado pelo plano de Frankfurt com a linha $\mathrm{CF}-\mathrm{Xi}$.

Média: $76^{\circ} \pm 3^{\circ}$.

Interpretação: ângulo diminuído é indicativo

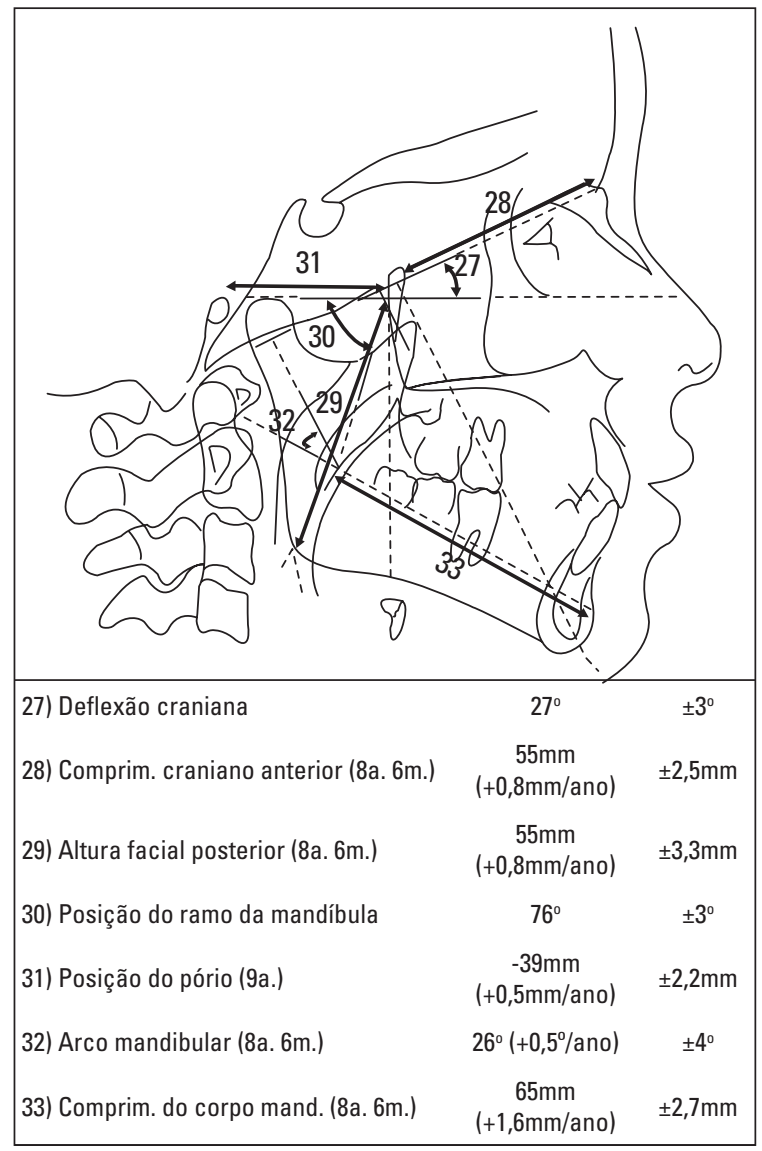

FIGURA 6 - Campo VI - estruturas internas.

de posição posterior do ramo. Ângulo aumentado é indicativo de associação com padrão latente de Classe III.

\section{1) Posição do pório}

Distância entre o ponto pório (Pr) e PTV, medida através do plano de Frankfurt.

Média: $-39 m m \pm 2,2 m m$ aos 9 anos. Aumenta $0,5 \mathrm{~mm}$ ao ano.

Interpretação: uma posição mesial do ramo pode ser devida a uma posição anterior do pório, associada com tendência à Classe III.

\section{2) Arco mandibular}

Ângulo formado através do eixo do corpo (Xi - Pm) pelo seu prolongamento e o eixo do côndilo (Xi-DC). 


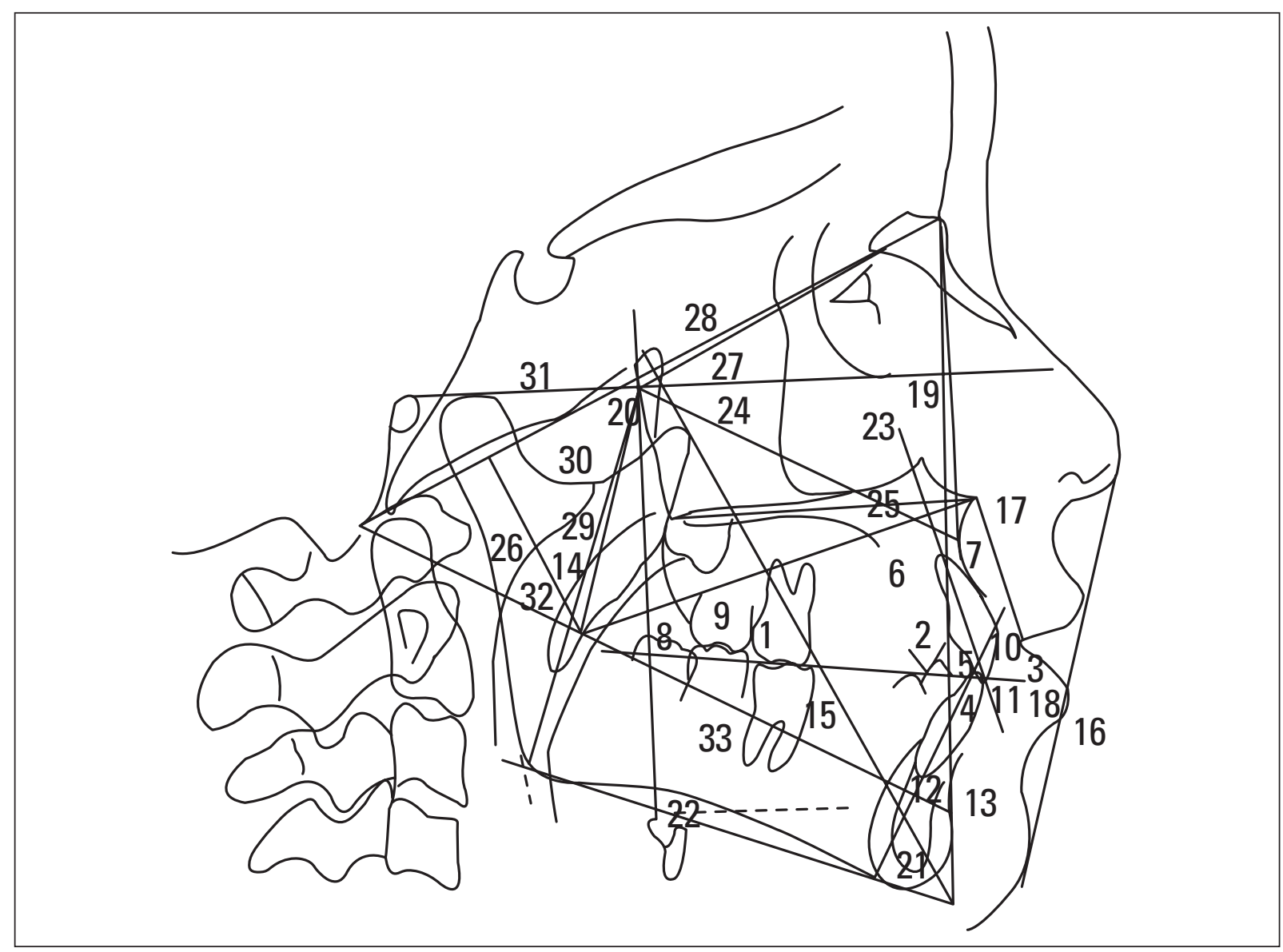

FIGURA 7 - Traçado completo (33 fatores), em norma lateral.

Média: $26^{\circ} \pm 4^{\circ}$ na idade de 8,5 anos. Aumenta $0,5^{\circ}$ por ano.

Interpretação: o aumento do valor do ângulo indica uma mandíbula de aspecto braquifacial. Quando abaixo do normal, representa uma tendência para uma mordida aberta.

\section{3) Comprimento do corpo mandibular}

Distância entre os pontos Xi e Pm.

Média: $65 \mathrm{~mm} \pm 2,7 \mathrm{~mm}$ para pacientes com 8,5 anos de idade. Aumenta $1,6 \mathrm{~mm}$ por ano.

Interpretação: avalia se o prognatismo ou retrognatismo é devido ao comprimento do corpo da mandibula.

A figura 7 mostra o traçado cefalométrico completo de Ricketts, com os 33 fatores (variáveis).

\section{RESULTADOS E DISCUSSÃO}

$O$ resultado da presente pesquisa, referente aos 6 campos com 33 fatores preconizados por Ricketts, em uma amostra de brasileiros, evidencia as diferenças em cada campo.

Para um melhor entendimento, discutiremos os fatores correspondentes por campo.

\section{Campo I - problemas dentários}

\section{Fator 1- relação molar}

Observou-se que os intervalos de confiança para as médias da relação molar de cada idade possuem pontos em comum, o que caracteriza serem essas médias estatisticamente iguais entre si. Os limites inferior e superior do intervalo de confiança, para as observações dessa medida, situam-se em torno de sua média geral, ao nível 
Tabela 1 - Relação molar segundo a idade (mm).

\begin{tabular}{cccccccc}
\hline $\begin{array}{c}\text { idade } \\
\text { (anos) }\end{array}$ & freq. & média & d.c. & mínimo & máximo & I. inf. & I. sup. \\
\hline 12 a 13 & 25 & $-1,72$ & 1,22 & -3 & 2,5 & $-2,22$ & $-1,22$ \\
13 a 14 & 25 & $-2,08$ & 1,02 & -3 & 2 & $-2,5$ & $-1,66$ \\
14 a 15 & 25 & $-2,08$ & 0,51 & -3 & -1 & $-2,29$ & $-1,87$ \\
geral & 75 & $-1,96$ & 0,96 & -3 & 2,5 & $-2,18$ & $-1,74$ \\
\hline
\end{tabular}

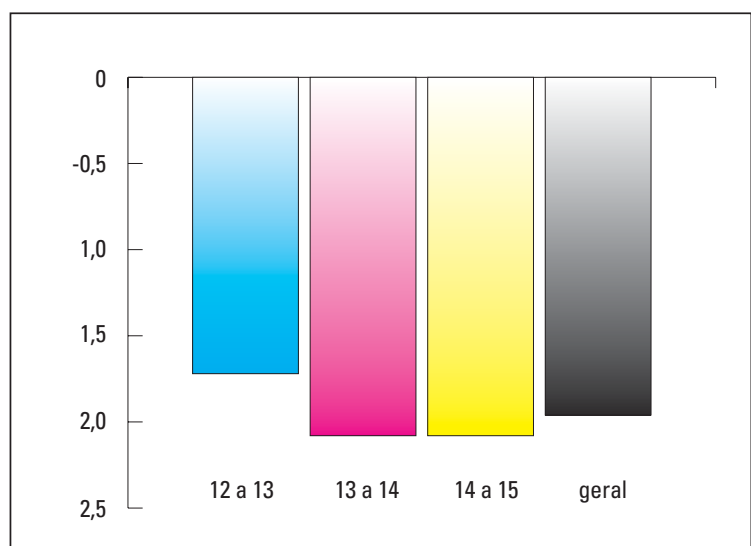

GRÁFICO 1 - Médias para a relação molar.

de 95\% (Tab. 1). Espera-se, então, com 95\% de probabilidade de acerto, que o indivíduo apresente as mesmas condições que os participantes dessa amostra tenha a relação molar compreendida entre $-3 \mathrm{~mm}$ e $2,5 \mathrm{~mm}$. Desse modo, pode-se dizer que essa medida possui um normal clínico igual a $-1,96 \mathrm{~mm} \pm 0,96 \mathrm{~mm}$, enquanto Ricketts et al. ${ }^{33}$ preconizavam um valor de $-3 \mathrm{~mm}$.

Para a idade de 12 a 13 anos, a amostra de 25 indivíduos apresentou, para a medida relação molar, o valor de $-1,72 \mathrm{~mm} \pm 1,22 \mathrm{~mm}$; de 13 a 14 anos o valor de $-2,08 \mathrm{~mm} \pm 1,02 \mathrm{~mm}$ e de 14 anos a 15 anos o valor de $-2,8 \mathrm{~mm} \pm 0,5 \mathrm{lmm}$. Sendo o normal clínico estabelecido por Ricketts et $\mathrm{al} .^{33}$ o valor de $-3 \mathrm{~mm} \pm 3 \mathrm{~mm}$, independentemente da idade em crescimento. Os molares da amostra se posicionaram mais anteriormente ao molar inferior, principalmente na média da amostra de 12 a 13 anos, seguida da média da amostra de 13 a 14 anos e da média da amostra de 14 a 15 anos, cujo valor é muito próximo ao preconizado por Ricketts (Tab. 1).
Tabela 2 - Relação dos caninos segundo a idade (mm).

\begin{tabular}{cccccccc}
\hline $\begin{array}{c}\text { idade } \\
\text { (anos) }\end{array}$ & freq. & média & d.c. & mínimo & máximo & I. inf. & I. sup. \\
\hline 12 a 13 & 25 & $-1,58$ & 0,51 & -2 & 0 & $-1,79$ & $-1,37$ \\
13 a 14 & 25 & $-1,58$ & 0,4 & $-2,5$ & -1 & $-1,75$ & $-1,41$ \\
14 a 15 & 25 & $-1,58$ & 0,37 & $-2,5$ & -1 & $-1,73$ & $-1,43$ \\
geral & 75 & $-1,58$ & 0,43 & $-2,5$ & 0 & $-1,68$ & $-1,48$ \\
\hline
\end{tabular}

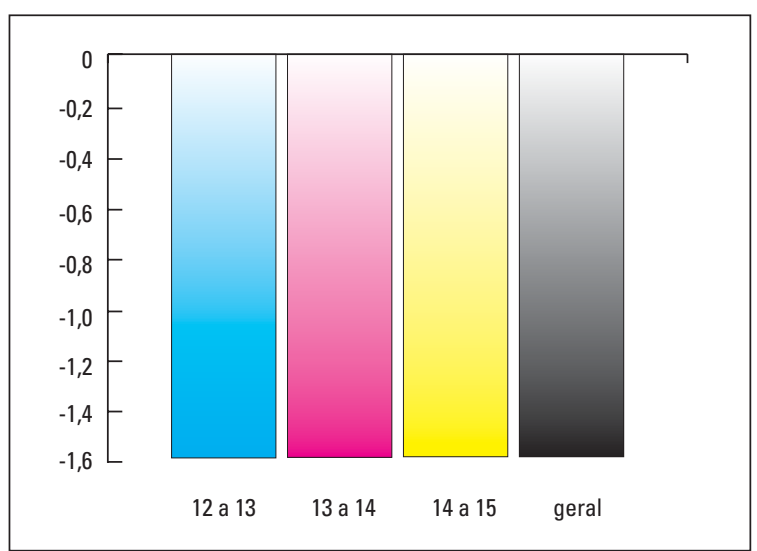

GRÁFICO 2 - Médias para a relação dos caninos.

Considerando a média geral dos 75 jovens do estudo, um indivíduo que apresente as mesmas condições que os participantes dessa amostra tem a relação molar compreendida entre $-2,5 \mathrm{~mm}$ e $-1,22 \mathrm{~mm}$, enquanto um indivíduo com as mesmas condições da amostra de Ricketts tem a relação molar compreendida entre $-3 \mathrm{~mm}$ e $-1 \mathrm{~mm}$, portanto há uma menor variabilidade de medida para este fator num indivíduo da amostra estudada.

\section{Fator 2 - relação dos caninos}

Verificou-se que as médias estatísticas são iguais entre si, mostrando claramente os intervalos de confiança para as observações dessa medida, em torno de sua média geral, com confiança de 95\% de probabilidade de acerto.

Assim, entre os 12 e 13 anos em 25 indivíduos a média foi de $-1,58 \mathrm{~mm} \pm 0,51 \mathrm{~mm}$ com um limite superior de $-1,79 \mathrm{~mm}$ e limite inferior de $-1,37 \mathrm{~mm}$. Entre os 13 e 14 anos a média de 25 indivíduos 
foi de $-1,58 \mathrm{~mm} \pm 0,4 \mathrm{~mm}$ com limite inferior de $-1,75 \mathrm{~mm}$ e limite superior de $-1,41 \mathrm{~mm}$, entre 14 e 15 anos a média foi de $-1,58 \mathrm{~mm} \pm 0,37 \mathrm{~mm}$ com limite inferior de $-1,73 \mathrm{~mm}$ e limite superior de $-1,43 \mathrm{~mm}$ (Tab. 2).

Dessa forma, pode-se dizer que essa medida possui um padrão igual a $-1,58 \mathrm{~mm}$, com desvio clínico de $0,43 \mathrm{~mm}$, enquanto um indivíduo com as mesmas características da média de Ricketts et al. ${ }^{33}$ tem a relação dos caninos de $-2, \mathrm{~mm} \pm 0 \mathrm{~mm}, \mathrm{o}$ que mostra que os indivíduos da presente amostra apresentam uma menor variabilidade de medida para este fator.

\section{Fator 3 - trespasse horizontal (Sobressaliência)}

Os intervalos de confiança para as médias do overjet, para as idades de 12 a 13 anos, 13 a 14 anos e 14 a 15 anos, possuem pontos em comum, o que caracteriza serem essas médias estatisticamente iguais entre si (Tab. 3). Os limites inferior e superior do intervalo de confiança, para as observações dessa medida, situam-se

Tabela 3 - Trespasse horizontal (Sobressaliência) segundo a idade (mm).

\begin{tabular}{cccccccc}
\hline $\begin{array}{c}\text { idade } \\
\text { (anos) }\end{array}$ & freq. & média & d.c. & mínimo & máximo & I. inf. & I. sup. \\
\hline 12 a 13 & 25 & 3,22 & 0,58 & 2 & 4 & 2,98 & 3,46 \\
13 a 14 & 25 & 3,16 & 0,67 & 1,5 & 4,5 & 2,88 & 3,44 \\
14 a 15 & 25 & 3,2 & 0,52 & 2 & 4,5 & 2,99 & 3,41 \\
geral & 75 & 3,19 & 0,59 & 1,5 & 4,5 & 3,06 & 3,33 \\
\hline
\end{tabular}

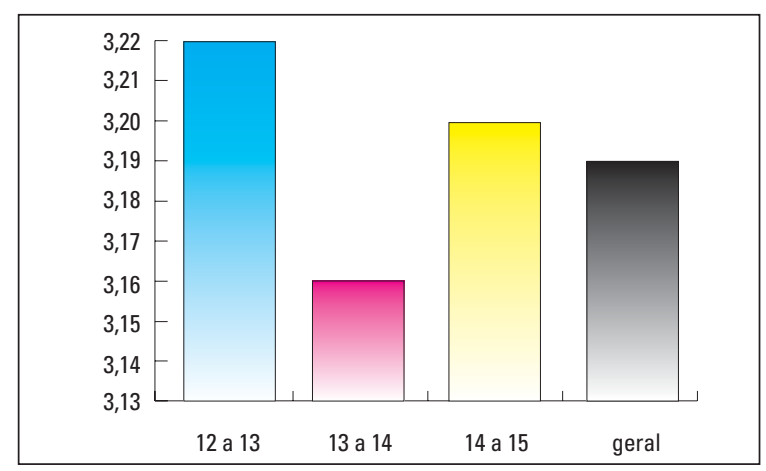

GRÁFICO 3 - Médias para a sobressaliência (Overjet). em torno de sua média geral, com confiança de 95\%. Espera-se, então, que, com $95 \%$ de probabilidade de acerto, um paciente que apresenta as mesmas condições que os participantes dessa amostra tenha o overjet compreendido entre $1,5 \mathrm{~mm}$ e $4,5 \mathrm{~mm}$.

Os 25 indivíduos da amostra estudada, com idade entre 12 e 13 anos, apresentaram, para a medida trespasse horizontal, o valor de $3,22 \mathrm{~mm} \pm 0,58 \mathrm{~mm} ; 3,16 \mathrm{~mm} \pm 0,67 \mathrm{~mm}$ dos 13 aos 14 anos e $3,20 \mathrm{~mm} \pm 0,52 \mathrm{~mm}$ dos 14 aos 15 anos, sendo mais altos em relação ao normal clínico estabelecido por Ricketts et al. ${ }^{31}$, que é de $2,5 \mathrm{~mm}$, com um desvio clínico de $\pm 2,5 \mathrm{~mm}$. Talvez a posição mais anterior dos molares e caninos superiores, em relação aos seus inferiores correspondentes, tenha feito com que o trespasse horizontal estivesse aumentado na medida da amostra estudada, em relação à média-padrão da amostra de Ricketts (Tab. 3).

O normal clínico na média total da amostra (75 indivíduos) foi de $3,19 \mathrm{~mm} \pm 0,59 \mathrm{~mm}$, significando que um indivíduo que apresenta as mesmas condições que os participantes dessa amostra tem o trespasse horizontal no valor compreendendo entre $1,5 \mathrm{~mm}$ e $4,5 \mathrm{~mm}$ (Tab. 3), enquanto indivíduos com as mesmas características da amostra de Ricketts tem o trespasse horizontal compreendido entre $0 \mathrm{~mm}$ e $5 \mathrm{~mm}$.

\section{Fator 4 - trespasse vertical (Sobremordida)}

$\mathrm{Na}$ tabela 4, os intervalos de confiança para as médias do trespasse vertical, segundo as idades, possuem pontos em comum, o que caracteriza serem essas médias estatisticamente iguais entre si. Os limites inferior e superior do intervalo de confiança, para as observações dessa medida, situam-se em torno de sua média geral, com confiança de $95 \%$. Espera-se, então, que, com $95 \%$ de probabilidade de acerto, um paciente que apresente as mesmas condições que os participantes dessa amostra tenha o trespasse vertical compreendido entre $1 \mathrm{~mm}$ e $5 \mathrm{~mm}$. 
Tabela 4 - Trespasse vertical (Sobremordida) segundo a idade (mm).

\begin{tabular}{cccccccc}
\hline $\begin{array}{c}\text { idade } \\
\text { (anos) }\end{array}$ & freq. & média & d. c. & mínimo & máximo & I. inf. & I. sup. \\
\hline 12 a 13 & 25 & 2,96 & 0,71 & 2 & 5 & 2,67 & 3,25 \\
13 a 14 & 25 & 2,82 & 0,76 & 1 & 4 & 2,51 & 3,13 \\
14 a 15 & 25 & 2,76 & 0,77 & 1,5 & 4 & 2,44 & 3,08 \\
geral & 75 & 2,85 & 0,74 & 1 & 5 & 2,68 & 3,02 \\
\hline
\end{tabular}

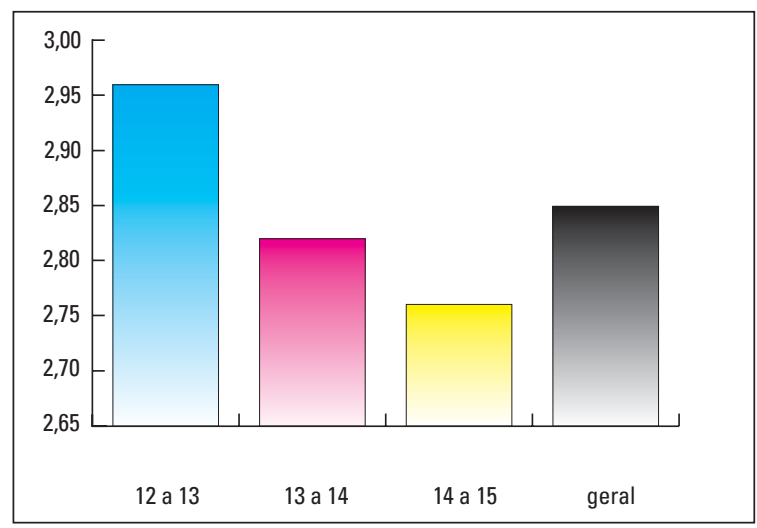

GRÁFICO 4 - Médias para a sobremordida (Overbite).

A amostra de 25 indivíduos na faixa etária de 12 a 13 anos apresentou, para a medida de trespasse vertical, o valor de $2,96 \mathrm{~mm} \pm 0,71 \mathrm{~mm}$; de $2,82 \mathrm{~mm} \pm 0,76 \mathrm{~mm}$ dos 13 aos 14 anos e de 2,76mm $\pm 0,77 \mathrm{~mm}$ dos 14 aos 15 anos (Tab. 4), acima do normal clínico estabelecido por Ricketts et $\mathrm{al} .{ }^{31}$, que é de $2,5 \mathrm{~mm} \pm 2 \mathrm{~mm}$.

A explicação para o aumento das medidas, nas médias obtidas na amostra, é o posicionamento mais anterior do molar superior em relação ao inferior, além da posição mais anterior também do canino superior em relação ao inferior e do aumento do normal clínico do trespasse horizontal.

A média geral, para a medida trespasse vertical (sobremordida), dos 75 indivíduos da amostra estudada correspondeu a $2,85 \mathrm{~mm}$ com desvio clínico de $\pm 0,74 \mathrm{~mm}$, significando que um indivíduo que apresente as mesmas condições que os participantes dessa amostra tem o trespasse horizontal compreendido entre $1 \mathrm{~mm}$ e $5 \mathrm{~mm}$ (Tab. 4),
Tabela 5 - Extrusão do incisivo central inferior até a linha APo segundo a idade (mm).

\begin{tabular}{cccccccc}
\hline $\begin{array}{c}\text { idade } \\
\text { (anos) }\end{array}$ & freq. & média & d.c. & mínimo & máximo & I. inf. & I. sup. \\
\hline 12 a 13 & 25 & 2,2 & 0,87 & 0,5 & 4,5 & 1,84 & 2,56 \\
13 a 14 & 25 & 2,3 & 1,06 & 0,5 & 5 & 1,86 & 2,74 \\
14 a 15 & 25 & 2,5 & 1,3 & 0 & 5 & 1,96 & 3,04 \\
geral & 75 & 2,33 & 1,08 & 0 & 5 & 2,09 & 2,58 \\
\hline
\end{tabular}

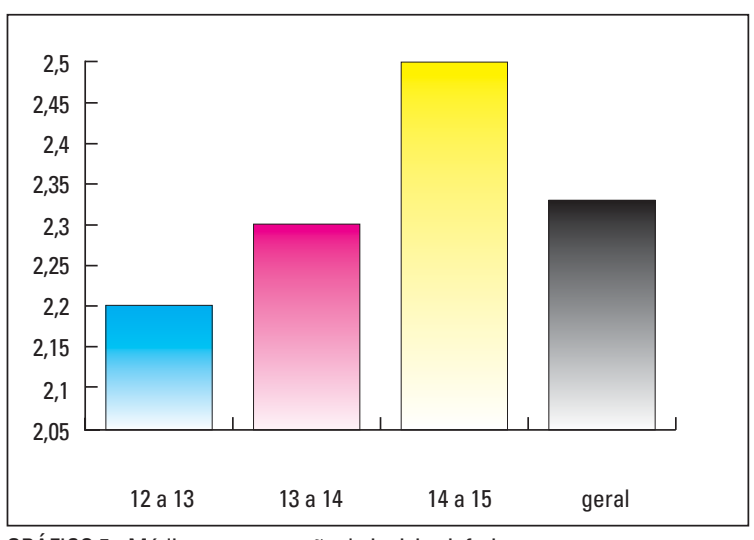

GRÁFICO 5 - Médias para extrusão do incisivo inferior.

enquanto indivíduos com as mesmas condições da amostra de Ricketts têm o trespasse vertical compreendido entre $0,5 \mathrm{~mm}$ e $4,5 \mathrm{~mm}$.

\section{Fator 5 - extrusão do incisivo inferior}

Os limites inferior e superior do intervalo de confiança, para extrusão do incisivo inferior, situam-se em torno da sua média geral com confiança de $95 \%$, possuindo pontos em comum, o que caracteriza serem essas médias estatisticamente iguais entre si.

Espera-se, então, que num indivíduo com as mesmas condições que os participantes dessa amostra, a extrusão dos incisivos inferiores esteja entre $0 \mathrm{~mm}$ e $5 \mathrm{~mm}$.

Para a faixa etária de 12 a 13 anos, a amostra de 25 indivíduos apresentou uma extrusão do incisivo inferior de $2,2 \mathrm{~mm} \pm 0,87 \mathrm{~mm} ; 2,3 \mathrm{~mm} \pm 1,06 \mathrm{~mm}$ de 13 a 14 anos e $2,5 \mathrm{~mm} \pm 1,3 \mathrm{~mm}$ de 14 a 15 anos. Todas as medidas médias estão acima do pa- 
Tabela 6 - Ângulo interincisivos segundo a idade (graus).

\begin{tabular}{cccccccc}
\hline $\begin{array}{c}\text { idade } \\
\text { (anos) }\end{array}$ & freq. & média & d.c. & mínimo & máximo & I. inf. & I. sup. \\
\hline 12 a 13 & 25 & 129,66 & 6,49 & 118 & 141,5 & 126,99 & 132,34 \\
13 a 14 & 25 & 127,3 & 6,2 & 110 & 144 & 124,74 & 129,86 \\
14 a 15 & 25 & 128,82 & 3,61 & 121 & 135,5 & 127,33 & 130,31 \\
geral & 75 & 128,59 & 5,6 & 110 & 144 & 127,31 & 129,88 \\
\hline
\end{tabular}

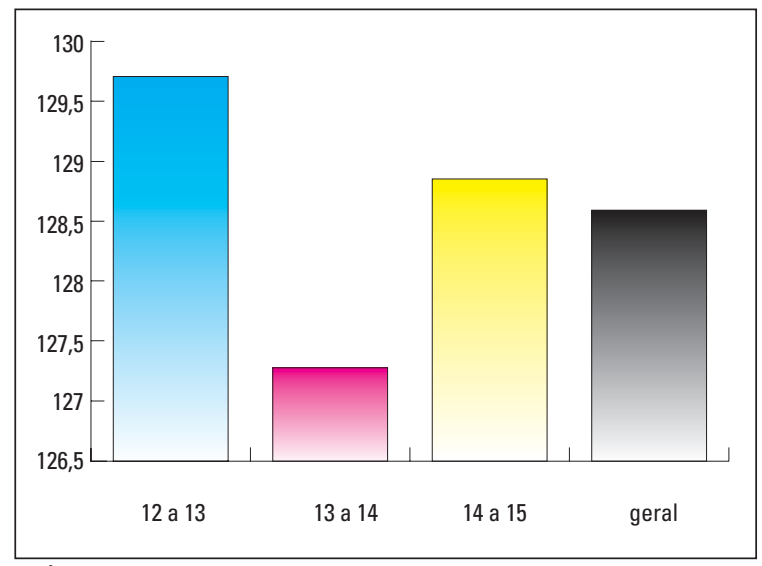

GRÁFICO 6 - Médias para o ângulo interincisivos.

drão de Ricketts et al. ${ }^{33}$, de $1,25 \mathrm{~mm}$ com um desvio clínico de $\pm 2 \mathrm{~mm}$.

Geralmente, nos indivíduos com trespasse horizontal aumentado, há maior extrusão dos incisivos inferiores, para buscar um contato com os incisivos superiores. Talvez isto explique uma maior extrusão dos incisivos na média da amostra estudada.

A média do total da amostra (75 indivíduos) apresentou um normal clínico igual a $2,33 \mathrm{~mm}$ e um desvio clínico de $\pm 1,08 \mathrm{~mm}$, significando que um indivíduo com as mesmas características que os participantes dessa amostra pode apresentar a extrusão do incisivo inferior compreendida entre $0 \mathrm{~mm}$ e $5 \mathrm{~mm}$, enquanto os indivíduos com as mesmas condições da amostra de Ricketts podem apresentar o trespasse vertical compreendido entre $0,75 \mathrm{~mm}$ e $3,25 \mathrm{~mm}$ (Tab. 5).

\section{Fator 6 - ângulo interincisivos}

A amostra de 25 indivíduos na faixa etária de 12 a 13 anos apresentou, para a medida ângulo interincisivos, o valor de $129,66^{\circ} \pm 6,49^{\circ} ; 127,30^{\circ} \pm 6,2^{\circ}$ de 13 a 14 anos e $128,82^{\circ} \pm 3,61^{\circ}$ de 14 a 15 anos (Tab. 6). Todas as medidas estão diminuídas, em relação à medida padrão estabelecida por Ricketts et al..$^{33}$, de $130^{\circ} \pm 10^{\circ}$, significando uma menor verticalização dos incisivos da amostra estudada.

Os 75 indivíduos da amostra apresentaram, para a medida ângulo interincisivos, um normal clínico de $128,59^{\circ}$, com desvio clínico de $\pm 5,6^{\circ}$, significando que um indivíduo que apresente as mesmas condições que os participantes dessa amostra tem o ângulo interincisivos compreendido entre $110^{\circ} \mathrm{e}$ $144^{\circ}$ (Tab. 6), enquanto o da amostra de Ricketts pode apresentar este fator com medida compreendida entre $120^{\circ}$ e $140^{\circ}$, com variabilidade bem menor que a da amostra estudada.

Pode-se dizer que, para essa amostra, o ângulo interincisivos possui um normal clínico igual a $128,59^{\circ} \pm 5,6^{\circ}$ (Tab. 6 ).

Comparando com os resultados obtidos por Downs $^{8}\left(135,4^{\circ} \pm 5,76^{\circ}\right)$, Steiner ${ }^{39}\left(130^{\circ}\right)$, Gresham $^{10}\left(131,04^{\circ} \pm 6,23^{\circ}\right.$ para neozelandeses de 7 a 9 anos), Civolani ${ }^{6}\left(129,40^{\circ}\right)$, Almeida e Vigorito $^{1}\left(129,3^{\circ} \pm 9,41^{\circ}\right)$ e $\operatorname{Rino}^{35}\left(129,46^{\circ}\right.$ aos 12 anos, $130^{\circ}$ aos 13 anos e $129,2^{\circ}$ aos 14 anos), os da amostra estudada apresentaram uma menor verticalização dos incisivos.

Em comparação com os achados de Gresham ${ }^{10}$ $\left(125,88^{\circ} \pm 5,84^{\circ}\right.$ em norte-americanos), Kowalski e Walker ${ }^{16}\left(129^{\circ}\right.$ dos 6 aos 26 anos), Siqueira ${ }^{38}$ $\left(126,4^{\circ}\right.$ aos 7 anos e $127,8^{\circ}$ aos 8 anos) e Rino ${ }^{36}$ $\left(124,80^{\circ}\right.$ aos 9 anos, $126,53^{\circ}$ aos 10 anos e $127,52^{\circ}$ aos 11 anos), os incisivos da amostra estudada apresentaram uma maior verticalização.

Em comparação com o resultado encontrado por Rino Neto $^{35}\left(122,45^{\circ}\right.$ dos 7 aos 9 anos), os incisivos da amostra estudada comprovaram uma verticalização altamente significante.

\section{Campo II - problemas esqueléticos}

\section{Fator 7 - convexidade do ponto $A$}

As médias da convexidade e seus intervalos de 
confiança para as idades de 12 a 13 anos, 13 a 14 anos e 14 a 15 anos, possuem pontos em comum, o que caracteriza serem essas médias estatisticamente iguais entre si. Os limites inferior e superior do intervalo de confiança, para as observações dessa medida, situam-se em torno de sua média geral, com confiança de 95\%. Espera-se, então, que, com $95 \%$ de probabilidade de acerto, um paciente que apresente as mesmas condições que os participantes dessa amostra tenha a convexidade compreendida entre $-2 \mathrm{~mm}$ e $7 \mathrm{~mm}$. Desse modo, pode-se dizer que essa medida possui uma média de $1,89 \mathrm{~mm} \pm 1,94 \mathrm{~mm}$ (Tab. 7).

Os 25 indivíduos com idade entre 12 e 13 anos apresentaram média da medida de convexidade do ponto A de $2,24 \mathrm{~mm} \pm 2,21 \mathrm{~mm} ; 2 \mathrm{~mm} \pm 1,45 \mathrm{~mm}$ para a idade de 13 a 14 anos e $1,44 \mathrm{~mm} \pm 2,07 \mathrm{~mm}$ para a idade de 14 a 15 anos (Tab. 7).

Segundo Ricketts et al. ${ }^{33}$, aos 8,5 anos de idade, a convexidade do ponto A deveria ser de $2 \mathrm{~mm} \pm 2 \mathrm{~mm}$, diminuindo $0,2 \mathrm{~mm}$ a cada ano, progressivamente com o crescimento. Portanto, aos 12 anos e 6 meses, a convexidade deveria ser de $1,2 \mathrm{~mm} ; 1 \mathrm{~mm}$ aos 13 anos e 6 meses e $0,8 \mathrm{~mm}$ aos 14 anos e 6 meses.

Embora nos indivíduos da amostra estudada o valor da medida da convexidade também tenha diminuído com o aumento da idade, o valor da média das três faixas etárias estudadas foi maior, isto é, houve a convexidade aumentada em relação à medida da média da pesquisa de Ricketts, para a idade correspondente.

Os 75 indivíduos da amostra apresentaram, para a medida convexidade do Ponto A, a média, na idade entre 13 e 14 anos, de $2 \mathrm{~mm}$ com um desvio clínico de $\pm 1,45 \mathrm{~mm}$, significando que um indivíduo que apresenta as mesmas condições que os participantes dessa amostra tem a convexidade compreendida entre $-2 \mathrm{~mm}$ e $7 \mathrm{~mm}$, enquanto um indivíduo com a característica da amostra de Ricketts tem a medida de convexidade compreendida entre $-1 \mathrm{~mm}$ e $3 \mathrm{~mm}$, isto é, uma variabilidade de medida bem menor em relação à amostra
Tabela 7 - Convexidade do ponto A segundo a idade (mm).

\begin{tabular}{cccccccc}
\hline $\begin{array}{c}\text { idade } \\
\text { (anos) }\end{array}$ & freq. & média & d.c. & mínimo & máximo & I. inf. & I. sup. \\
\hline 12 a 13 & 25 & 2,24 & 2,21 & $-2,00$ & 7,00 & 1,33 & 3,15 \\
13 a 14 & 25 & 2,00 & 1,45 & $-1,50$ & 5,50 & 1,40 & 2,60 \\
& & & & \\
14 a 15 & 25 & 1,44 & 2,07 & $-2,00$ & 5,00 & 0,58 & 2,30 \\
geral & 75 & 1,89 & 1,94 & $-2,00$ & 7,00 & 1,45 & 2,34 \\
\hline
\end{tabular}

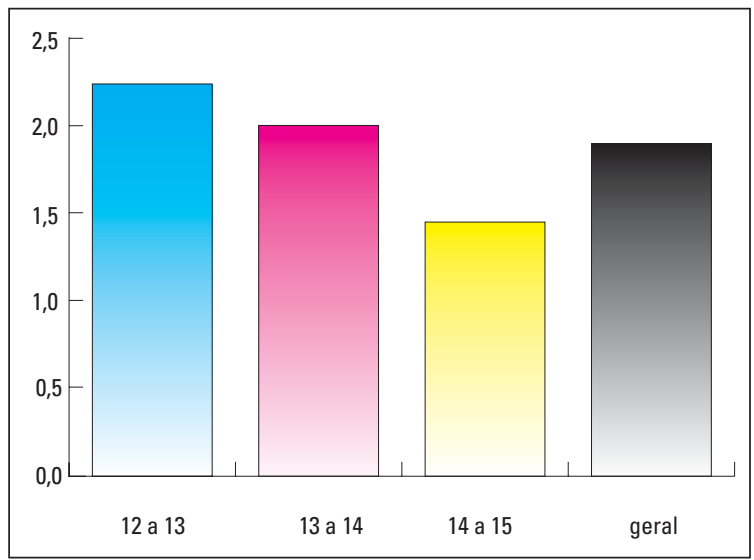

GRÁFICO 7 - Médias para a convexidade do ponto "A".

estudada (Tab. 7). Comparando com o estudo de Ricketts, em indivíduos entre 7 e 11 anos, observase que a média de convexidade de $4,2 \mathrm{~mm}$, encontrada por ele, foi muito maior do que a média da amostra estudada. O estudo do mesmo autor, com adultos entre 18 e 36 anos, comprovou um normal clínico de 1,6mm para a convexidade do ponto A, aproximado-se da média do valor encontrado na amostra estudada.

Fator 8 - altura facial inferior (Altura da dentição)

As médias da altura facial inferior para as idades de 12 a 13 anos, de 13 a 14 anos e 14 a 15 anos, para os intervalos de confiança, possuem pontos em comum, o que caracterizou serem essas médias estatisticamente iguais entre si. Os limites inferior e superior do intervalo de confiança, para as observações dessa medida, situam-se em torno de sua média geral, com confiança de 95\%. 
Tabela 8 - Altura facial inferior (Altura da dentição) segundo a idade (graus).

\begin{tabular}{cccccccc}
\hline $\begin{array}{c}\text { idade } \\
\text { (anos) }\end{array}$ & freq. & média & d.c. & mínimo & máximo & I. inf. & I. sup. \\
\hline 12 a 13 & 25 & 42,42 & 2,39 & 37,50 & 47,50 & 41,43 & 43,41 \\
13 a 14 & 25 & 42,24 & 3,19 & 37,40 & 48,50 & 40,92 & 43,55 \\
14 a 15 & 25 & 42,88 & 2,36 & 39,00 & 47,00 & 41,91 & 43,85 \\
geral & 75 & 42,51 & 2,65 & 37,40 & 48,50 & 41,90 & 43,12 \\
\hline
\end{tabular}

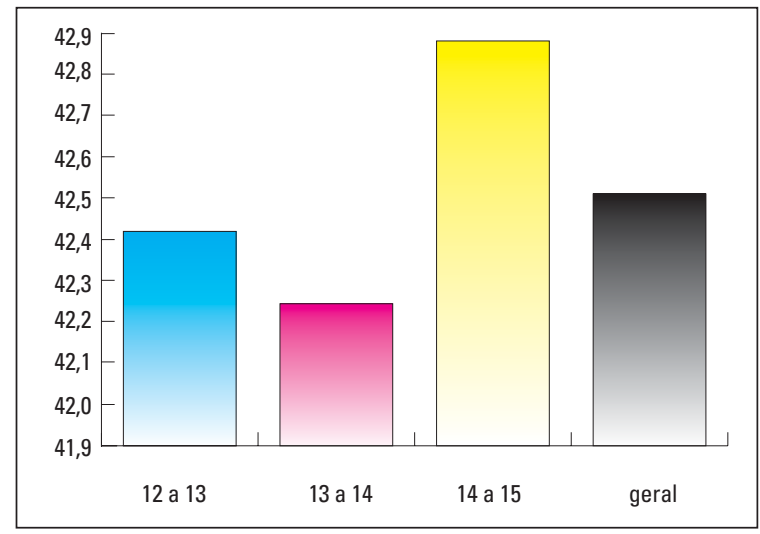

GRÁFICO 8 - Médias para a altura da dentição.

Espera-se, então, que, com 95\% de probabilidade de acerto, um paciente que apresente as mesmas condições que os participantes dessa amostra, tenha a altura facial inferior compreendida entre $37,5^{\circ}$ e $48,5^{\circ}$. Desse modo, pode-se dizer que essa medida possui um normal clínico igual a $42,51^{\circ} \pm 2,65^{\circ}$ (Tab. 8).

Para a medida altura facial inferior, a amostra de 25 indivíduos apresentou o valor de $42,42^{\circ} \pm 2,39^{\circ}$ de 12 a 13 anos; $42,24^{\circ} \pm 3,19^{\circ}$ de 13 a 14 anos e $42,88^{\circ} \pm 2,36^{\circ}$ de 14 a 15 anos, com média de 14 anos e 6 meses (Tab. 8). Valores bem menores daqueles $47^{\circ}$ preconizados por Ricketts et al. ${ }^{33}$, indicando um crescimento mais horizontal dos maxilares, nos indivíduos da amostra estudada.

\section{Campo III - problemas dentoesqueléticos}

Fator 9 - posição do primeiro molar a Pt.V

Com $95 \%$ de probabilidade de acerto, um in-
Tabela 9 - Posição do $1^{\circ}$ molar superior a PTV, segundo a idade $(\mathrm{mm})$.

\begin{tabular}{cccccccc}
\hline $\begin{array}{c}\text { idade } \\
\text { (anos) }\end{array}$ & freq. & média & d. c. & mínimo & máximo & I. inf. & I. sup. \\
\hline 12 a 13 & 25 & 17,16 & 3,51 & 9,50 & 22,00 & 15,71 & 18,61 \\
13 a 14 & 25 & 18,76 & 3,34 & 12,50 & 25,00 & 17,38 & 20,14 \\
14 a 15 & 25 & 18,62 & 3,73 & 10,50 & 28,00 & 17,08 & 20,16 \\
geral & 75 & 18,18 & 3,56 & 9,50 & 28,00 & 17,36 & 19,00 \\
\hline
\end{tabular}

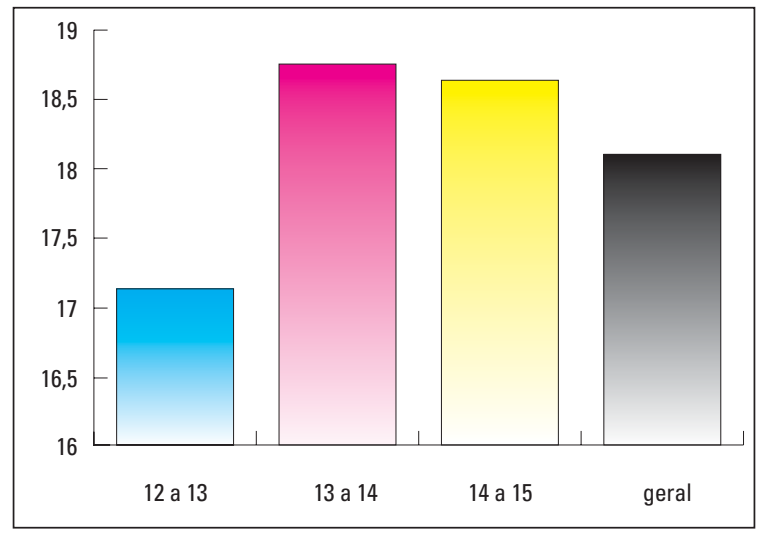

GRÁFICO 9 - Médias para a posição do $1^{\circ} \mathrm{molar}$ superior.

divíduo que apresente as mesmas condições que a amostra, tem a posição do primeiro molar, compreendida entre $9,5 \mathrm{~mm}$ e $28 \mathrm{~mm}$ com um normal clínico de $18,18 \mathrm{~mm} \pm 3,56 \mathrm{~mm}$.

A amostra de 25 indivíduos mostrou para 6PTV, $17,16 \mathrm{~mm} \pm 3,51 \mathrm{~mm}$ na faixa etária de $12 \mathrm{a}$ 13 anos; $18,76 \mathrm{~mm} \pm 3,34 \mathrm{~mm}$ entre 13 e 14 anos; e $18,62 \mathrm{~mm} \pm 3,73 \mathrm{~mm}$ com idade de 14 a 15 anos. Valores aumentados quando comparados com Ricketts et al. ${ }^{31}$, que na média de idade de 12 a 13 anos correspondem a $15,5 \mathrm{~mm} ; 16,5 \mathrm{~mm}$ entre 13 e 14 anos e $17,5 \mathrm{~mm}$ entre 14 e 15 anos (Tab. 9).

No presente estudo, a posição do primeiro molar Pt.V. teve um valor médio entre $9,5 \mathrm{~mm}$ e $28 \mathrm{~mm}$, enquanto na amostra de Ricketts et al. ${ }^{33} \mathrm{o}$ valor médio é entre $13,5 \mathrm{~mm}$ e $19,5 \mathrm{~mm}$.

Fator 10 - protrusão do incisivo central inferior

Na tabela 10 observa-se que, com 95\% de pro- 
Tabela 10 - Protrusão do incisivo central inferior segundo a idade $(\mathrm{mm})$.

\begin{tabular}{cccccccc}
\hline $\begin{array}{c}\text { idade } \\
\text { (anos) }\end{array}$ & freq. & média & d.c. & mínimo & máximo & I. inf. & I. sup. \\
\hline 12 a 13 & 25 & 2,04 & 1,88 & $-1,50$ & 6,00 & 1,27 & 2,81 \\
13 a 14 & 25 & 2,26 & 1,72 & $-1,00$ & 6,00 & 1,55 & 2,97 \\
14 a 15 & 25 & 2,34 & 1,73 & $-1,50$ & 7,00 & 1,63 & 3,05 \\
geral & 75 & 2,21 & 1,76 & $-1,50$ & 7,00 & 1,81 & 2,62 \\
\hline
\end{tabular}

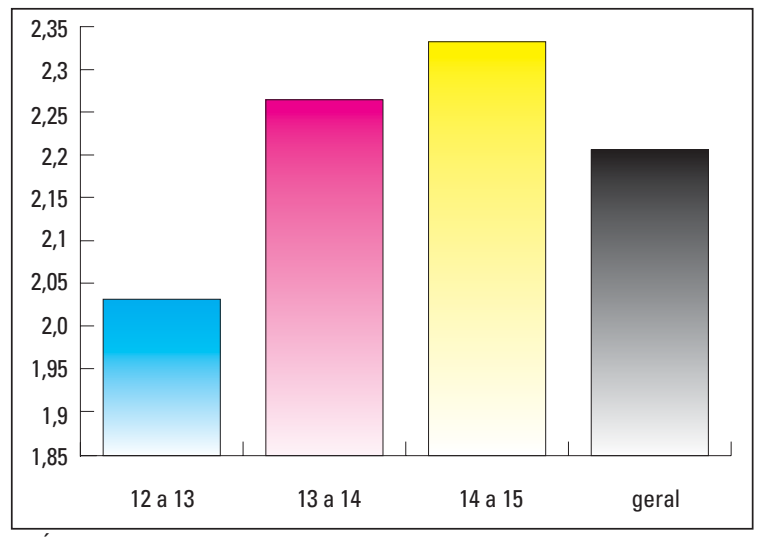

GRÁFICO 10 - Médias para a protrusão do incisivo central inferior.

babilidade de acerto, a amostra teve uma protusão de $2,21 \mathrm{~mm} \pm 1,76 \mathrm{~mm}$, podendo-se afirmar que possui um normal clínico igual a $2 \mathrm{~mm} \pm 5 \mathrm{~mm}$.

Para 25 indivíduos analisados, com idade de 12 a 13 anos, a protusão do incisivo central inferior foi de $2,04 \mathrm{~mm} \pm 1,88 \mathrm{~mm} ; 2,26 \mathrm{~mm} \pm 1,72 \mathrm{~mm}$ com 13 a 14 anos e $2,34 \mathrm{~mm} \pm 1,73 \mathrm{~mm}$ com 14 a 15 anos (Tab. 10), que são valores bem superiores aos encontrados por Ricketts et al. ${ }^{31}$, que são de $1 \mathrm{~mm}$ independente da idade.

\section{Fator 11 - protrusão do incisivo central inferior}

Com 95\% de probabilidade de acerto, a protusão do incisivo central superior está compreendida entre $1 \mathrm{~mm}$ e $10 \mathrm{~mm}$, com uma média de $5,31 \mathrm{~mm} \pm 1,89 \mathrm{~mm}$. Para a idade de 12 a 13 anos, a média foi de $5,18 \mathrm{~mm} \pm 1,93 \mathrm{~mm}$; $5,26 \mathrm{~mm} \pm 1,97 \mathrm{~mm}$ com idade 13 a 14 anos e $5,48 \mathrm{~mm} \pm 1,82 \mathrm{~mm}$ com 14 a 15 anos (Tab. 11), indicando uma posição mais anterior do que
Tabela 11 - Protrusão do incisivo central superior até a linha APo segundo a idade (mm).

\begin{tabular}{cccccccc}
\hline $\begin{array}{c}\text { idade } \\
\text { (anos) }\end{array}$ & freq. & média & d.c. & mínimo & máximo & I.inf. & I. sup. \\
\hline 12 a 13 & 25 & 5,18 & 1,93 & 1,00 & 9,00 & 4,38 & 5,98 \\
13 a 14 & 25 & 5,26 & 1,97 & 2,50 & 9,50 & 4,45 & 6,07 \\
14 a 15 & 25 & 5,48 & 1,82 & 1,50 & 10,00 & 4,73 & 6,23 \\
geral & 75 & 5,31 & 1,89 & 1,00 & 10,00 & 4,87 & 5,74 \\
\hline
\end{tabular}

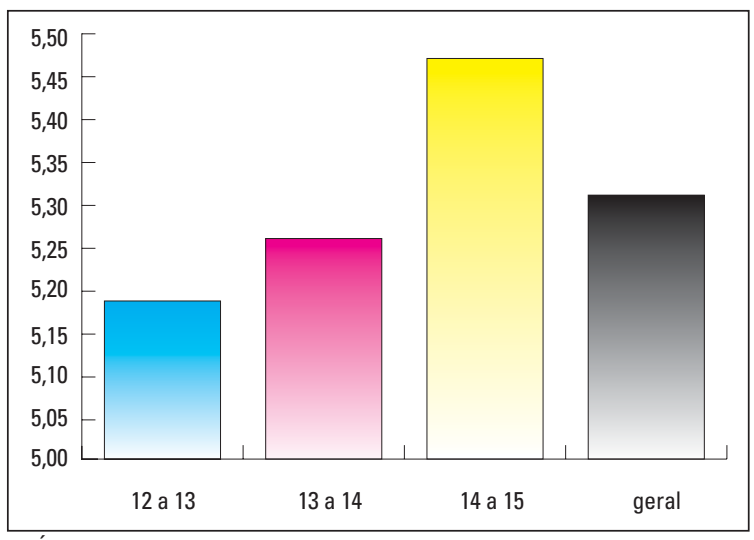

GRÁFICO 11 - Médias para a protrusão do incisivo central superior.

a encontrada por Ricketts et al. ${ }^{33}$, que foi de $3,5 \mathrm{~mm} \pm 2,5 \mathrm{~mm}$.

Fator 12 - inclinição do incisivo central inferior até a linha APo

A inclinação do incisivo central inferior está compreendida entre $17^{\circ}$ e $31,5^{\circ}$.

Desse modo, pode-se dizer que, esta medida possui um normal clínico igual a $24,09^{\circ} \pm 3,26^{\circ}$ (Tab. 12).

Quando avaliada por faixa etária, verificamos que a amostra com 25 indivíduos com idade entre 12 e 13 anos apresentou uma inclinação do incisivo central inferior de $23,80^{\circ} \pm 4,01^{\circ} ; 24,88^{\circ} \pm 3,03^{\circ}$ dos 13 aos 14 anos e $23,60^{\circ} \pm 2,58^{\circ}$ para a faixa de 14 a 15 anos (Tab. 12).

Esses valores angulares indicam um incisivo inferior com maior inclinação para vestibular ao plano A-Po em relação à medida padrão preconizada por Ricketts et al.$^{33}$, que é de $22^{\circ} \pm 4^{\circ}$. 
Tabela 12 - Inclinação do incisivo central inferior até a linha APo segundo a idade (graus).

\begin{tabular}{cccccccc}
\hline $\begin{array}{c}\text { idade } \\
\text { (anos) }\end{array}$ & freq. & média & d. c. & mínimo & máximo & I. inf. & I. sup. \\
\hline 12 a 13 & 25 & 23,80 & 4,01 & 17,00 & 31,00 & 22,15 & 25,45 \\
13 a 14 & 25 & 24,88 & 3,03 & 20,00 & 31,00 & 23,63 & 26,13 \\
14 a 15 & 25 & 23,60 & 2,58 & 20,00 & 31,50 & 22,53 & 24,67 \\
geral & 75 & 24,09 & 3,26 & 17,00 & 31,50 & 23,34 & 24,84 \\
\hline
\end{tabular}

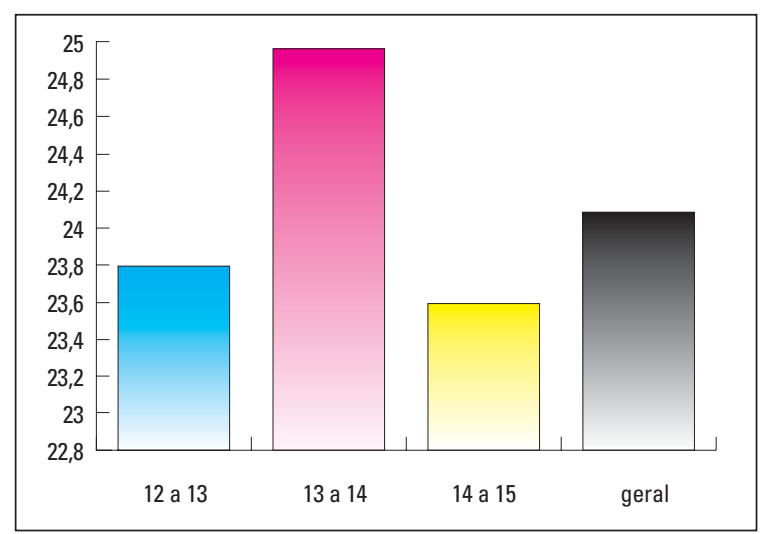

GRÁFICO 12 - Médias para a inclinação do incisivo central inferior.

\section{Fator 13 - inclinação do incisivo central} superior

Os limites inferiores e superiores do intervalo de confiança, para as observações dessa medida, situam-se em torno de sua média, com $95 \%$ de probabilidade de acerto, estando compreendidos entre $17^{\circ}$ e $36,5^{\circ}$, com média de $27,75^{\circ} \pm 5,08^{\circ}$ (Tab. 13).

Para as idades de 12 a 13 anos, a inclinação do incisivo superior foi de $27,46^{\circ} \pm 5,23^{\circ}$, $28,38^{\circ} \pm 5,55^{\circ}$ para a faixa de 13 a 14 anos e $27,42^{\circ} \pm 4,56^{\circ}$ para a faixa de 14 a 15 anos, suavemente verticalizada, em relação à preconizada por Ricketts et al. ${ }^{33}$ que é de $28^{\circ} \pm 4^{\circ}$.

\section{Fator 14 - plano oclusal-Xi}

$\mathrm{Na}$ avaliação de 75 indivíduos, os limites do intervalo de confiança inferior e superior situamse em torno de sua média geral, isto é, $-8 \mathrm{~mm}$ e $4 \mathrm{~mm}$, como pode ser visto na tabela 14 . Dessa
Tabela 13 - Inclinação do incisivo central superior até a linha APo segundo a idade (graus).

\begin{tabular}{cccccccc}
\hline $\begin{array}{c}\text { idade } \\
\text { (anos) }\end{array}$ & freq. & média & d. c. & mínimo & máximo & I. inf. & I. sup. \\
\hline 12 a 13 & 25 & 27,46 & 5,23 & 17,00 & 36,00 & 25,30 & 29,62 \\
13 a 14 & 25 & 28,38 & 5,55 & 20,00 & 36,50 & 26,09 & 30,67 \\
14 a 15 & 25 & 27,42 & 4,56 & 18,00 & 35,00 & 25,54 & 29,30 \\
geral & 75 & 27,75 & 5,08 & 17,00 & 36,50 & 26,59 & 28,92 \\
\hline
\end{tabular}

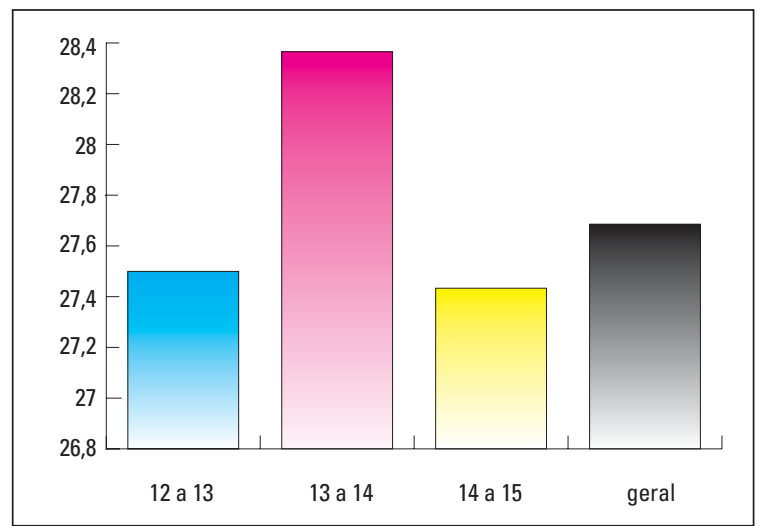

GRÁFICO 13 - Médias para a inclinação do incisivo central superior.

forma podemos afirmar que essa medida possui uma média de $-0,85 \mathrm{~mm} \pm 2,6 \mathrm{~mm}$.

A medida do plano oclusal ao ramo Xi segundo Ricketts et al. ${ }^{33}$ variou com o crescimento e aos 9 anos e 6 meses deveria ser de $0 \mathrm{~mm} \pm 3 \mathrm{~mm}$, com o plano oclusal passando exatamente no ponto Xi. Essa medida diminuiu com o crescimento $0,5 \mathrm{~mm}$ por ano. Aos 12 anos e 6 meses Ricketts et al. ${ }^{31}$ afirmaram que deveria medir $-1,5 \mathrm{~mm},-2 \mathrm{~mm}$ aos 13 anos e 6 meses e $-2,5 \mathrm{~mm}$ aos 14 anos e 6 meses. Entretanto ao avaliarmos os 75 indivíduos, na faixa etária entre 12 a 13 anos encontramos para a medida plano oclusal ao ramo $\mathrm{Xi}$ o valor de $-0,73 \mathrm{~mm} \pm 2,31 \mathrm{~mm}$; $-0,68 \mathrm{~mm} \pm 2,30 \mathrm{~mm}$ com 13 a 14 anos e $-1,14 \mathrm{~mm} \pm 3,16 \mathrm{~mm}$ com a idade de 14 a 15 anos, todos os valores das medidas indicando que o plano oclusal passa acima dos valores normais estabelecidos por Ricketts et al. ${ }^{33}$ 
Tabela 14 - Plano oclusal-Xi segundo a idade (mm).

\begin{tabular}{cccccccc}
\hline $\begin{array}{c}\text { idade } \\
\text { (anos) }\end{array}$ & freq. & média & d.c. & mínimo & máximo & I. inf. & I. sup. \\
\hline 12 a 13 & 25 & $-0,73$ & 2,31 & $-6,50$ & 2,00 & $-1,70$ & 0,25 \\
13 a 14 & 25 & $-0,68$ & 2,30 & $-6,00$ & 3,50 & $-1,63$ & 0,27 \\
14 a 15 & 25 & $-1,14$ & 3,16 & $-8,00$ & 4,00 & $-2,45$ & 0,17 \\
geral & 75 & $-0,85$ & 2,60 & $-8,00$ & 4,00 & $-1,45$ & $-0,25$ \\
\hline
\end{tabular}

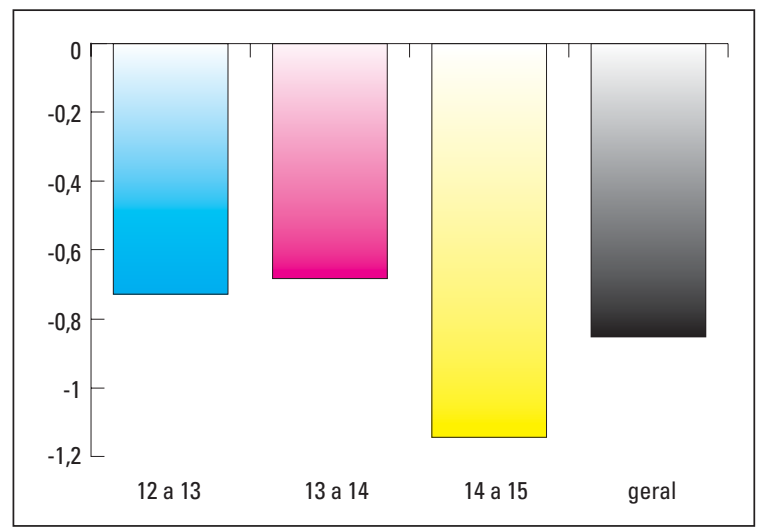

GRÁFICO 14 - Médias para o plano oclusal ao ramo-Xi.

\section{Fator 15 - inclinação do plano oclusal}

$\mathrm{Na}$ tabela 15 observa-se que essas medidas, segundo as idades consideradas, são estatisticamente iguais entre si.

Segundo Ricketts et al..$^{33}$ o fator inclinação do plano oclusal também se altera com a idade, sendo de $22^{\circ}$ o valor médio aos 8 anos, com desvio clínico de $\pm 4^{\circ}$ diminuindo $0,5^{\circ}$ por ano. Observou-se na amostra $21,56^{\circ} \pm 2,39^{\circ}$ entre 12 e 13 anos, $19,86^{\circ} \pm 4,44^{\circ}$ entre 13 e 14 anos e $21,70^{\circ} \pm 3,65^{\circ}$ entre 14 e 15 anos. A média geral de 75 indivíduos da amostra apresentou um valor de $21,04^{\circ} \pm 3,64^{\circ}$, não indicando diferenças estatisticamente significantes com a medida de Ricketts.

\section{Campo IV - problemas estéticos Fator 16 - posição labial}

A variável posição labial é muito importante para a definição da estética facial, que se altera com
Tabela 15 - Inclinação do plano oclusal segundo a idade (graus).

\begin{tabular}{cccccccc}
\hline $\begin{array}{c}\text { idade } \\
\text { (anos) }\end{array}$ & freq. & média & d.c. & mínimo & máximo & I. inf. & I. sup. \\
\hline 12 a 13 & 25 & 21,56 & 2,39 & 18,00 & 26,00 & 20,58 & 22,54 \\
13 a 14 & 25 & 19,86 & 4,44 & 2,00 & 25,50 & 18,03 & 21,69 \\
14 a 15 & 25 & 21,70 & 3,65 & 17,50 & 31,00 & 20,20 & 23,20 \\
geral & 75 & 21,04 & 3,64 & 2,00 & 31,00 & 20,20 & 21,88 \\
\hline
\end{tabular}

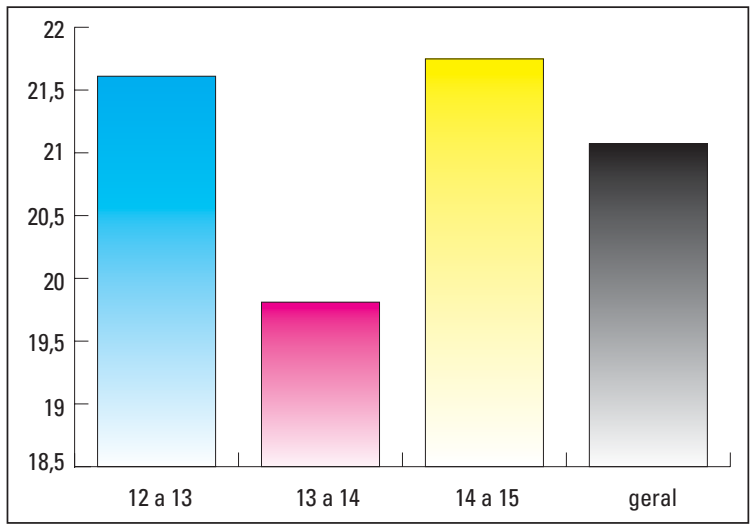

GRÁFICO 15 - Médias para a inclinação do plano oclusal.

o crescimento, segundo Ricketts et al..$^{33}$

A distância do lábio inferior ao plano estético aumenta $0,2 \mathrm{~mm}$ por ano e aos 8 anos e 6 meses deve ser de $2 \mathrm{~mm}$. Estatisticamente a amostra para a posição labial está compreendida entre $-6 \mathrm{~mm}$ e $5,5 \mathrm{~mm}$, tendo uma média de $-0,95 \mathrm{~mm} \pm 2,37 \mathrm{~mm}$ (Tab. 16).

Segundo Ricketts ${ }^{34}$ aos 12 anos deveria medir $-2,8 \mathrm{~mm},-3 \mathrm{~mm}$ aos 13 anos e $-3,2 \mathrm{~mm}$ aos 14 anos.

Quando comparada com 75 indivíduos do presente estudo, constatou-se que dos 12 aos 13 anos foi de $-1,02 \mathrm{~mm} \pm 2,07 \mathrm{~mm}$, com o lábio inferior localizado mais anteriormente em relação ao normal clínico estabelecido por Ricketts nessa mesma idade. Dos 13 aos 14 anos, o lábio inferior se localiza apenas $-0,48 \mathrm{~mm} \pm 2,62 \mathrm{~mm}$ atrás do plano E, portanto menor do que deveria, encontrando-se mais posterior do que entre 12 e 13 anos. Dos 14 aos 15 anos, constatou-se a média 
Tabela 16 - Posição labial segundo a idade (mm).

\begin{tabular}{cccccccc}
\hline $\begin{array}{c}\text { idade } \\
\text { (anos) }\end{array}$ & freq. & média & d. c. & mínimo & máximo & I. inf. & I. sup. \\
\hline 12 a 13 & 25 & $-1,02$ & 2,07 & $-6,00$ & 3,00 & $-1,88$ & $-0,16$ \\
13 a 14 & 25 & $-0,48$ & 2,62 & $-5,00$ & 5,50 & $-1,56$ & 0,60 \\
14 a 15 & 25 & $-1,36$ & 2,40 & $-6,00$ & 3,50 & $-2,35$ & $-0,37$ \\
geral & 75 & $-0,95$ & 2,37 & $-6,00$ & 5,50 & $-1,50$ & $-0,41$ \\
\hline
\end{tabular}

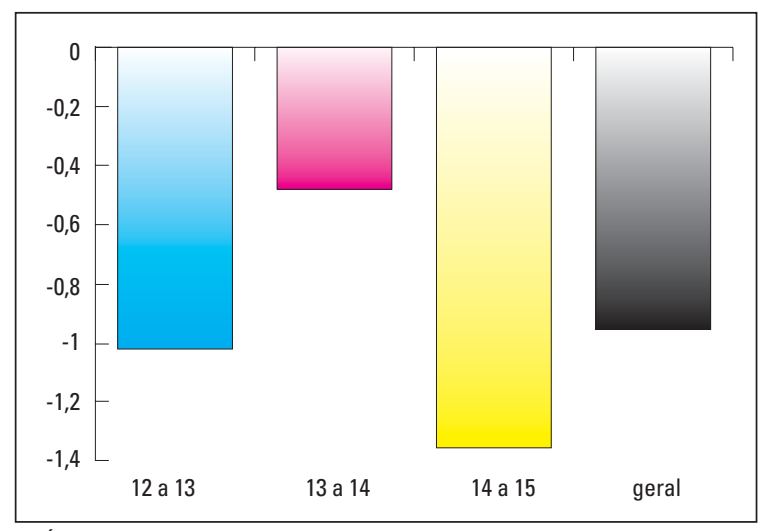

GRÁFICO 16 - Médias para a posição labial.

de $-1,36 \mathrm{~mm} \pm 2,4 \mathrm{~mm}$. Uma das questões talvez seja que a espessura do lábio, devido à miscigenação dos 25 indivíduos que compuseram essa média de idade, tenha feito com que o lábio inferior se posicionasse mais anteriormente.

A média geral dos 75 indivíduos, para a medida posição de lábio inferior, foi de $-0,95 \mathrm{~mm}$ $\pm 2,37 \mathrm{~mm}$, atrás do plano E (Tab. 16).

\section{Fator 17 - comprimento do lábio superior}

A tabela 17 mostra a distribuição por média de idade e os limites de confiança. O intervalo de confiança para a idade entre 12 e 13 anos possui limites menores do que dos 13 aos 14 anos e 14 a 15 anos, apresentando uma média geral igual a $26,74 \mathrm{~mm} \pm 2,40 \mathrm{~mm}$.

Para a idade de 12 a 13 anos, a amostra de 25 indivíduos apresentou um valor de $25,52 \mathrm{~mm} \pm 2,33 \mathrm{~mm} ; 27,58 \mathrm{~mm} \pm 2,72 \mathrm{~mm}$ de 13 a 14 anos e $27,12 \mathrm{~mm} \pm 1,58 \mathrm{~mm}$ entre 14 e 15 anos,
Tabela 17 - Comprimento do lábio superior segundo a idade $(\mathrm{mm})$.

\begin{tabular}{cccccccc}
\hline $\begin{array}{c}\text { idade } \\
\text { (anos) }\end{array}$ & freq. & média & d.c. & mínimo & máximo & I. inf. & I. sup. \\
\hline 12 a 13 & 25 & 25,52 & 2,33 & 21,00 & 29,50 & 24,56 & 26,48 \\
13 a 14 & 25 & 27,58 & 2,72 & 24,00 & 34,00 & 26,46 & 28,70 \\
14 a 15 & 25 & 27,12 & 1,58 & 24,50 & 31,50 & 26,47 & 27,77 \\
geral & 75 & 26,74 & 2,40 & 21,00 & 34,00 & 26,19 & 27,29 \\
\hline
\end{tabular}

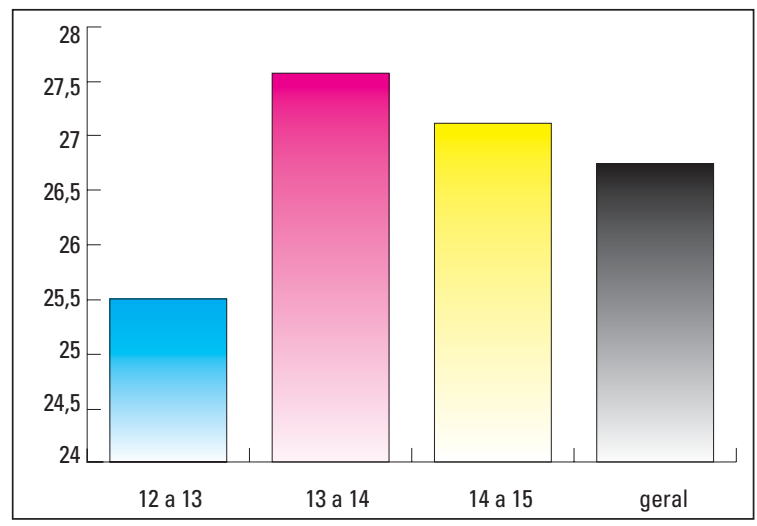

GRÁFICO 17 - Médias para o comprimento do lábio superior.

valores aumentados em relação ao preconizado por Ricketts et al..$^{31}$, que foi de $24 \mathrm{~mm} \pm 2 \mathrm{~mm}$, independente da idade do indivíduo.

\section{Fator 18 - ponto união interlabial-plano oclusal}

$\mathrm{Na}$ amostra estudada os valores da união interlabial-plano oclusal estão compreendidos entre $-8 \mathrm{~mm}$ e $4,5 \mathrm{~mm}$, com uma média de $-3,46 \mathrm{~mm} \pm 2,31 \mathrm{~mm}$ (Tab. 18).

Assim é que, a amostra de 25 indivíduos, com idade de 12 a 13 anos, apresentou um valor de $-2,82 \mathrm{~mm} \pm 2,97 \mathrm{~mm} ;-3,82 \mathrm{~mm} \pm 2,01 \mathrm{~mm}$ de 13 a 14 anos e - 3,74mm $\pm 1,70 \mathrm{~mm}$ de 14 e 15 anos. Segundo Ricketts et al..$^{33}$ essa medida diminui $0,1 \mathrm{~mm}$ com o crescimento, tendo como referência a idade de 8 anos e 6 meses com valor de $-3,5 \mathrm{~mm} \pm 2 \mathrm{~mm}$. Portanto na média de idade entre 12 a 13 anos, deveria ser de $-3,06 \mathrm{~mm} \pm 2,97 \mathrm{~mm} ;-3,82 \mathrm{~mm} \pm 2,01 \mathrm{~mm}$ entre 13 e 14 anos e $-3,74 \mathrm{~mm} \pm 1,70 \mathrm{~mm}$ entre 14 e 15 anos. Entretanto, em todas as medidas de idades 
Tabela 18 - Ponto união interlabial-plano oclusal segundo a idade $(\mathrm{mm})$.

\begin{tabular}{cccccccc}
\hline $\begin{array}{c}\text { idade } \\
\text { (anos) }\end{array}$ & freq. & média & d.c. & mínimo & máximo & I. inf. & I. sup. \\
\hline 12 a 13 & 25 & $-2,82$ & 2,97 & $-7,00$ & 4,50 & $-4,05$ & $-1,59$ \\
13 a 14 & 25 & $-3,82$ & 2,01 & $-8,00$ & $-1,00$ & $-4,65$ & $-2,99$ \\
14 a 15 & 25 & $-3,74$ & 1,70 & $-7,00$ & 1,00 & $-4,44$ & $-3,04$ \\
geral & 75 & $-3,46$ & 2,31 & $-8,00$ & 4,50 & $-3,99$ & $-2,93$ \\
\hline
\end{tabular}

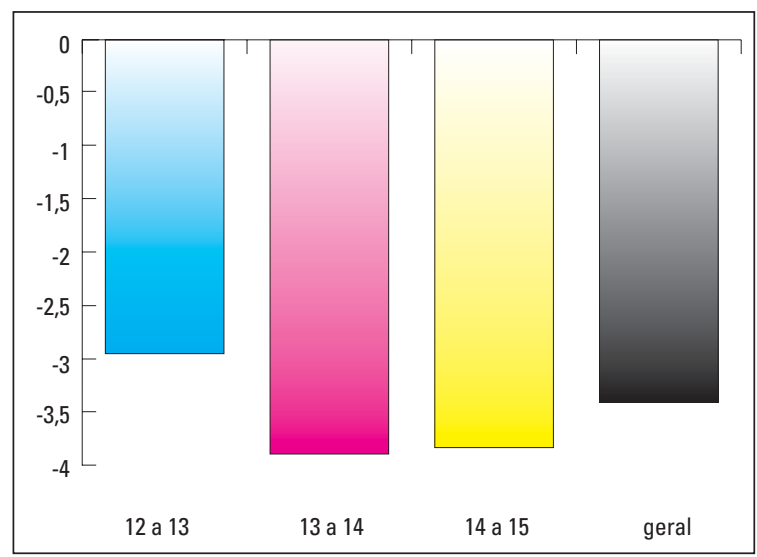

GRÁFICO 18 - Médias para o ponto união interlabial-plano oclusal.

da amostra, o plano oclusal se posicionou mais inferiormente em relação à medida clínica encontrada por Ricketts.

\section{Campo V - relação craniofacial}

\section{Fator 19 - profundidade facial}

Este estudo mostrou que a profundidade facial está compreendida entre $81^{\circ}$ e $98,5^{\circ}$ com um normal clínico de $89,23^{\circ}$ e desvio clínico de $\pm 3,25^{\circ}$, com $95 \%$ de acerto (Tab. 19).

Entre 12 e 13 anos os 25 indivíduos da amostra apresentaram um valor de $89^{\circ} \pm 3,66^{\circ}$, $89,54^{\circ} \pm 3,21^{\circ}$ entre 13 e 14 anos e $89,14^{\circ} \pm 2,96^{\circ}$ entre 14 e 15 anos (Tab. 19). Segundo Ricketts et al..$^{33}$ aos 9 anos teria o valor médio de $87^{\circ} \pm 3^{\circ}$; aumentando $0,33^{\circ}$ ao ano.

$\mathrm{Na}$ amostra em leucodermas americanos essa medida foi de $88,2^{\circ}$ aos 12 anos e 6 meses; $88,5^{\circ}$ aos 13 anos e 6 meses e $88,7^{\circ}$ aos 14 anos e 6 meses respectivamente.
Tabela 19 - Profundidade facial segundo a idade (graus).

\begin{tabular}{cccccccc}
\hline $\begin{array}{c}\text { idade } \\
\text { (anos) }\end{array}$ & freq. & média & d. c. & mínimo & máximo & I. inf. & I. sup. \\
\hline 12 a 13 & 25 & 89,00 & 3,66 & 81,00 & 95,50 & 87,49 & 90,51 \\
13 a 14 & 25 & 89,54 & 3,21 & 85,00 & 97,00 & 88,22 & 90,86 \\
14 a 15 & 25 & 89,14 & 2,96 & 83,00 & 98,50 & 87,92 & 90,36 \\
geral & 75 & 89,23 & 3,25 & 81,00 & 98,50 & 88,48 & 89,97 \\
\hline
\end{tabular}

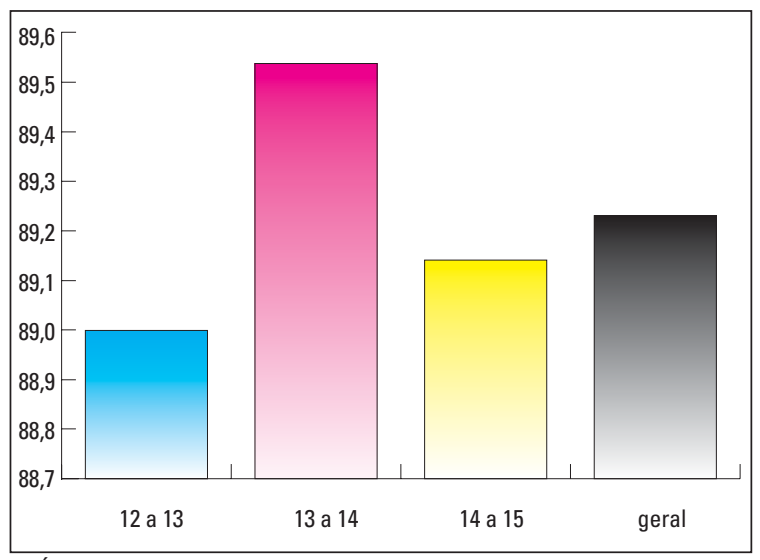

GRÁFICO 19 - Médias para a profundidade facial.

Quando comparadas essas medidas com as do presente estudo, observa-se que na amostra estudada, a mandíbula está mais anteriormente posicionada, principalmente aos 13 anos e 6 meses, cujas médias são maiores do que a média dos 14 anos e 6 meses.

Em relação a outros autores como Downs ${ }^{8}$, cujo valor encontrado foi de $87,8^{\circ} \pm 3,57^{\circ}$, Hirsch et al..$^{13}$ que encontraram $87,63^{\circ} \pm 4,48^{\circ}$ no gênero masculino e $84,55^{\circ} \pm 5,01^{\circ}$ no feminino, Bishara ${ }^{4}$ que encontrou um valor de $83^{\circ} \pm 2,8^{\circ}$ aos 8 anos e 6 meses, Rino Neto ${ }^{35}$ que encontrou um valor de $86,5^{\circ} \pm 3,39^{\circ}$ em indivíduos de 7 a 9 anos, observase que os valores iniciais encontrados pela amostra foram maiores, significando uma posição mais anterior do mento.

\section{Fator 20 - eixo facial}

$\mathrm{Na}$ avaliação deste ângulo observou-se que, com 95\% de acerto, esta medida ficou compre- 
Tabela 20 - Eixo facial segundo a idade (graus).

\begin{tabular}{cccccccc}
\hline $\begin{array}{c}\text { idade } \\
\text { (anos) }\end{array}$ & freq. & média & d.c. & mínimo & máximo & I. inf. & I. sup. \\
\hline 12 a 13 & 25 & 92,70 & 3,67 & 86,50 & 99,50 & 91,19 & 94,21 \\
13 a 14 & 25 & 93,82 & 2,95 & 87,00 & 101,00 & 92,60 & 95,04 \\
14 a 15 & 25 & 92,80 & 2,88 & 87,00 & 98,50 & 91,61 & 93,99 \\
geral & 75 & 93,11 & 3,18 & 86,50 & 101,00 & 92,37 & 93,84 \\
\hline
\end{tabular}

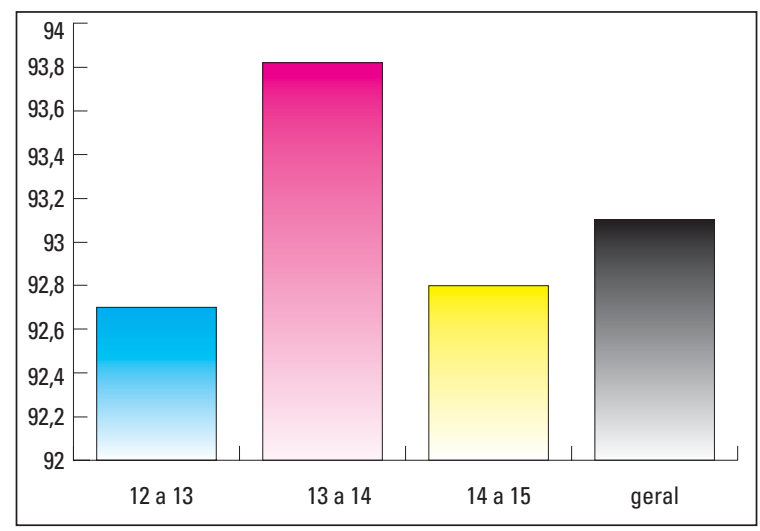

GRÁFICO 20 - Médias para o eixo facial.

endida entre $86,50^{\circ}$ e $101^{\circ}$ com valor médio de $93,11^{\circ} \pm 3,18^{\circ}$. Assim apresentou um valor de $92,70^{\circ} \pm 3,67^{\circ}$ entre 12 e 13 anos, $93,82^{\circ} \pm 2,95^{\circ}$ entre 13 e 14 anos e $92,8^{\circ} \pm 2,88^{\circ}$ entre 14 e 15 anos, valores maiores se comparados ao valor estabelecido por Ricketts et al. ${ }^{33}\left(90^{\circ} \pm 3,5^{\circ}\right)$, o que mostra um crescimento mais horizontal dos indivíduos da amostra estudada (Tab. 20).

\section{Fator 21 - cone facial}

$\mathrm{O}$ valor médio para essa medida está contido entre $61^{\circ}$ e $76,5^{\circ}$ com média de $68,11^{\circ} \pm 3,30^{\circ}$, enquanto na amostra de Ricketts et al. ${ }^{33}$ estava contido entre $54,5^{\circ}$ e $71,5^{\circ}$, com média de $63^{\circ} \pm 3,5^{\circ}$. Assim é que entre 12 e 13 anos apresentou um valor de $67,28^{\circ} \pm 3,05^{\circ}, 68,90^{\circ} \pm 2,90^{\circ}$ entre 13 e 14 anos e $68,14^{\circ} \pm 3,82^{\circ}$ entre 14 e 15 anos, mostrando uma tendência de crescimento horizontal nos indivíduos da amostra estudada (Tab. 21).
Tabela 21 - Cone facial segundo a idade (graus).

\begin{tabular}{cccccccc}
\hline $\begin{array}{c}\text { idade } \\
\text { (anos) }\end{array}$ & freq. & média & d. c. & mínimo & máximo & I. inf. & I. sup. \\
\hline 12 a 13 & 25 & 67,28 & 3,05 & 61,00 & 72,00 & 66,02 & 68,54 \\
13 a 14 & 25 & 68,90 & 2,90 & 62,50 & 74,50 & 67,70 & 70,10 \\
14 a 15 & 25 & 68,14 & 3,82 & 61,50 & 76,50 & 66,56 & 69,72 \\
geral & 75 & 68,11 & 3,30 & 61,00 & 76,50 & 67,35 & 68,87 \\
\hline
\end{tabular}

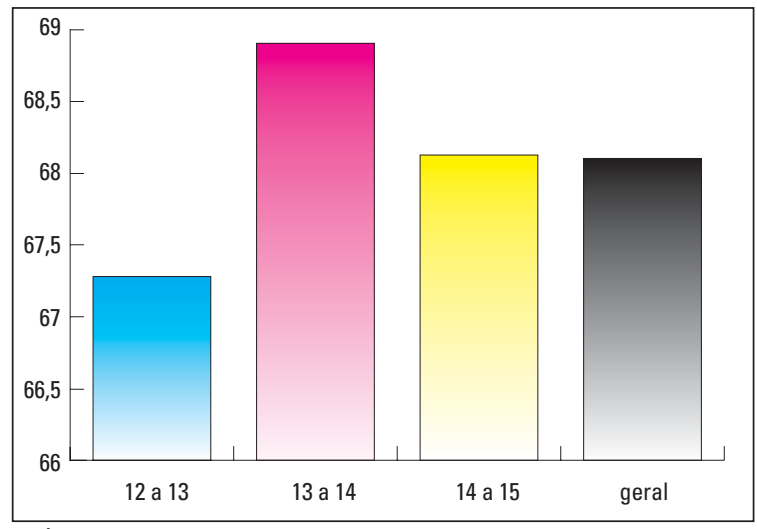

GRÁFICO 21 - Médias para o cone facial.

\section{Fator 22 - ângulo do plano mandibular}

Essa medida tem um valor médio de $23,42^{\circ} \pm 4,70^{\circ}$, estando compreendido entre $10^{\circ} \mathrm{e}$ $35^{\circ}$ (Tab. 22), enquanto na amostra de Ricketts et al. ${ }^{33}$ o valor médio é de $24,65^{\circ} \pm 4^{\circ}$.

A amostra com idade entre 12 e 13 anos apresentou um valor de $24,46^{\circ} \pm 4,17^{\circ} ; 21,86^{\circ} \pm 4,94^{\circ}$ entre 13 e 14 anos e $23,94^{\circ} \pm 4,73^{\circ}$ entre 14 e 15 anos. Valores menores quando comparados com a amostra de Ricketts et al. ${ }^{33}$, que apresentou um valor médio de $26,35^{\circ}$ aos 12 anos e 6 meses; $26,65^{\circ}$ aos 13 anos e 6 meses e $26,95^{\circ}$ aos 14 anos e 6 meses.

A amostra estudada apresenta uma tendência de crescimento horizontal se acentuando aos 13 anos e 6 meses.

Quando comparada com Downs ${ }^{8}$, a média de $21,6^{\circ} \pm 3,2^{\circ}$ da amostra estudada tem uma tendência de crescimento vertical. Quando comparado a Higley ${ }^{12}$ que apresentou uma média de 
Tabela 22 - Ângulo do plano mandibular segundo a idade (graus).

\begin{tabular}{cccccccc}
\hline $\begin{array}{c}\text { idade } \\
\text { (anos) }\end{array}$ & freq. & média & d.c. & mínimo & máximo & I. inf. & I. sup. \\
\hline 12 a 13 & 25 & 24,46 & 4,17 & 17,50 & 35,00 & 22,74 & 26,18 \\
13 a 14 & 25 & 21,86 & 4,94 & 10,00 & 30,00 & 19,82 & 23,90 \\
14 a 15 & 25 & 23,94 & 4,73 & 13,00 & 32,00 & 21,99 & 25,89 \\
geral & 75 & 23,42 & 4,70 & 10,00 & 35,00 & 22,34 & 24,50 \\
\hline
\end{tabular}

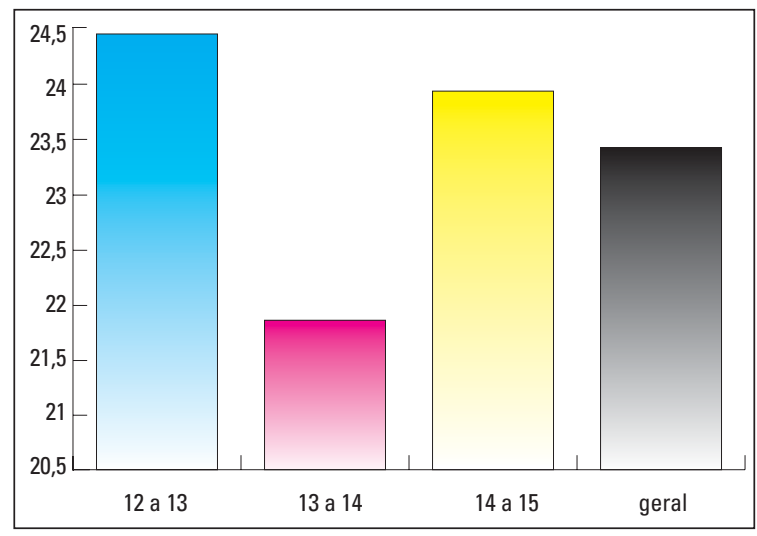

GRÁFICO 22 - Médias para o ângulo do plano mandibular.

$26,9^{\circ} \pm 3,4^{\circ}$ e ao estudo de Ricketts et al. ${ }^{33}$ em meninas de 4 a 8 anos, que apresentou um valor médio de $28,3^{\circ} \pm 4^{\circ}$, a amostra estudada apresentou uma tendência de crescimento mais horizontal.

\section{Fator 23 - profundidade da maxila}

Para esse ângulo, que tem um limite mínimo de $83,50^{\circ}$ e máximo de $99^{\circ}$, a média observada foi de $91,09^{\circ} \pm 3,37^{\circ}$ (Tab. 23). Sendo que entre 12 e 13 anos os 25 indivíduos dessa faixa etária apresentaram um valor de $91,44^{\circ} \pm 3,68^{\circ}$; $91,52^{\circ} \pm 2,97^{\circ}$ entre 13 e 14 anos e $90,30^{\circ} \pm 3,41^{\circ}$ entre 14 e 15 anos. Em todas as idades os valores foram menores que a média preconizada por Ricketts et al. ${ }^{33}$ de $90^{\circ} \pm 3^{\circ}$.

\section{Fator 24 - altura maxilar}

O estudo dessa medida com $95 \%$ de acerto está compreendido entre $50^{\circ}$ e $66,50^{\circ}$ com uma
Tabela 23 - Profundidade maxilar segundo a idade (graus).

\begin{tabular}{cccccccc}
\hline $\begin{array}{c}\text { idade } \\
\text { (anos) }\end{array}$ & freq. & média & d. c. & mínimo & máximo & I. inf. & I. sup. \\
\hline 12 a 13 & 25 & 91,44 & 3,68 & 83,50 & 98,50 & 89,92 & 92,96 \\
13 a 14 & 25 & 91,52 & 2,97 & 86,50 & 98,00 & 90,29 & 92,75 \\
14 a 15 & 25 & 90,30 & 3,41 & 83,50 & 99,00 & 88,89 & 91,71 \\
geral & 75 & 91,09 & 3,37 & 83,50 & 99,00 & 90,31 & 91,86 \\
\hline
\end{tabular}

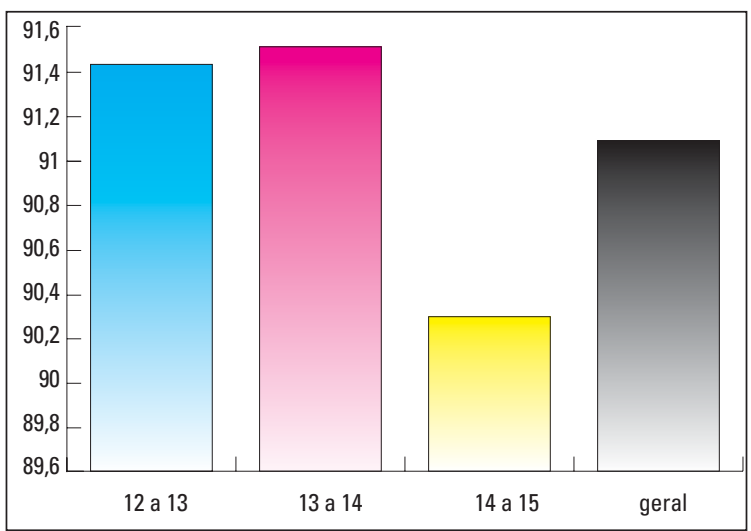

GRÁFICO 23 - Médias para a profundidade maxilar.

média de $56,22^{\circ} \pm 3,54^{\circ}$. Assim é que entre 12 e 13 anos a média foi de $56,74^{\circ} \pm 4,08^{\circ} ; 54,96^{\circ} \pm 2,90^{\circ}$ dos 13 aos 14 anos e $56,96^{\circ} \pm 3,32^{\circ}$ entre 14 e 15 anos. Segundo Ricketts et al. ${ }^{33}$ aos 9 anos de idade deveria medir $53^{\circ} \pm 3^{\circ}$ com um aumento de $0,4^{\circ}$ por ano, sendo $54,4^{\circ}$ aos 12 anos e 6 meses; $54,8^{\circ}$ aos 13 anos e 6 meses e $55,2^{\circ}$ aos 14 anos e 6 meses. Na média observou-se que em todas as faixas etárias as medidas da amostra estudada foram maiores do que preconizam Ricketts et al. ${ }^{33}$, mostrando um crescimento mais vertical da maxila.

Fator 25 - plano palatino/plano horizontal de Frankfurt

O valor médio para esse ângulo está contido entre $-7^{\circ}$ e $10,5^{\circ}$, com média de $0,63^{\circ} \pm 3,06^{\circ}$. Entre 12 e 13 anos apresentou um valor médio de $1,52^{\circ} \pm 3,1^{\circ} ; 0,20^{\circ} \pm 3,45^{\circ}$ entre 13 e 14 anos e $0,18^{\circ} \pm 2,46^{\circ}$ entre 14 e 15 anos (Tab. 25), 
Tabela 24 - Altura maxilar segundo a idade (graus).

\begin{tabular}{cccccccc}
\hline $\begin{array}{c}\text { idade } \\
\text { (anos) }\end{array}$ & freq. & média & d.c. & mínimo & máximo & I. inf. & I. sup. \\
\hline 12 a 13 & 25 & 56,74 & 4,08 & 51,00 & 65,00 & 55,06 & 58,42 \\
13 a 14 & 25 & 54,96 & 2,90 & 50,00 & 61,00 & 53,76 & 56,16 \\
14 a 15 & 25 & 56,96 & 3,32 & 50,00 & 62,50 & 55,59 & 58,33 \\
geral & 75 & 56,22 & 3,54 & 50,00 & 66,50 & 55,41 & 57,03 \\
\hline
\end{tabular}

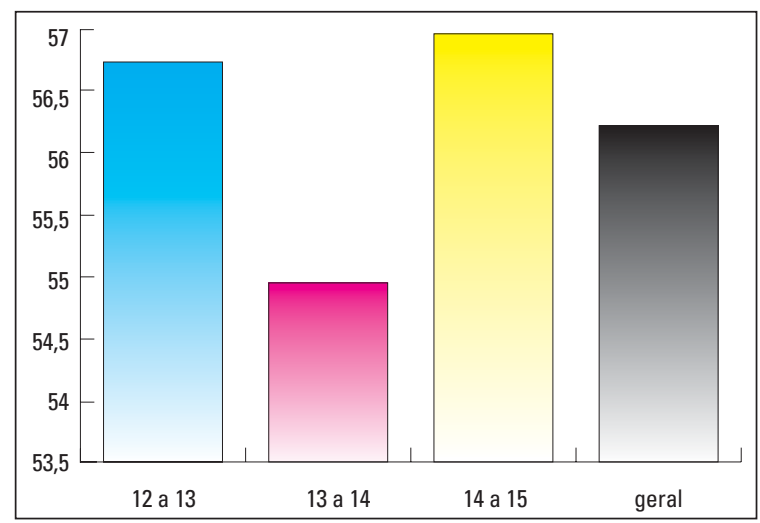

GRÁFICO 24 - Médias para a altura maxilar.

enquanto Ricketts et al. ${ }^{31}$ estabeleceram um valor médio de $1^{\circ} \pm 3,5^{\circ}$. Portanto, na amostra estudada observou-se uma maior rotação da maxila no sentido anti-horário quando comparada com a medida de Ricketts et al. ${ }^{33}$, tanto na região espinha nasal anterior como na região da espinha nasal posterior.

Por outro lado, verifica-se que nas médias de idade entre 13 e 14 anos e 14 e 15 anos, os valores encontrados no presente estudo foram menores que os propostos por Ricketts et al. ${ }^{33}$, significando uma posição mais horizontal do plano palatal em relação ao plano de Frankfurt.

\section{Fator 26 - altura facial total}

Observou-se que, com 95\% de probabilidade de acerto, a altura facial total ficou compreendida entre $47^{\circ}$ e $67^{\circ}$ (Tab. 26) com um normal clínico de $55,62^{\circ} \pm 4,24^{\circ}$ diferindo das medidas de Ricketts et. $\mathrm{al} .^{33}$, que apresentaram um valor compreen-
Tabela 25 - Plano palatino/plano horizontal Frankfurt, segundo a idade (graus).

\begin{tabular}{cccccccc}
\hline $\begin{array}{c}\text { idade } \\
\text { (anos) }\end{array}$ & freq. & média & d.c. & mínimo & máximo & I. inf. & I. sup. \\
\hline 12 a 13 & 25 & 1,52 & 3,10 & $-6,00$ & 7,50 & 0,24 & 2,80 \\
13 a 14 & 25 & 0,20 & 3,45 & $-7,00$ & 10,50 & $-1,22$ & 1,62 \\
14 a 15 & 25 & 0,18 & 2,46 & $-4,00$ & 4,50 & $-0,84$ & 1,20 \\
geral & 75 & 0,63 & 3,06 & $-7,00$ & 10,50 & $-0,07$ & 1,34 \\
\hline
\end{tabular}

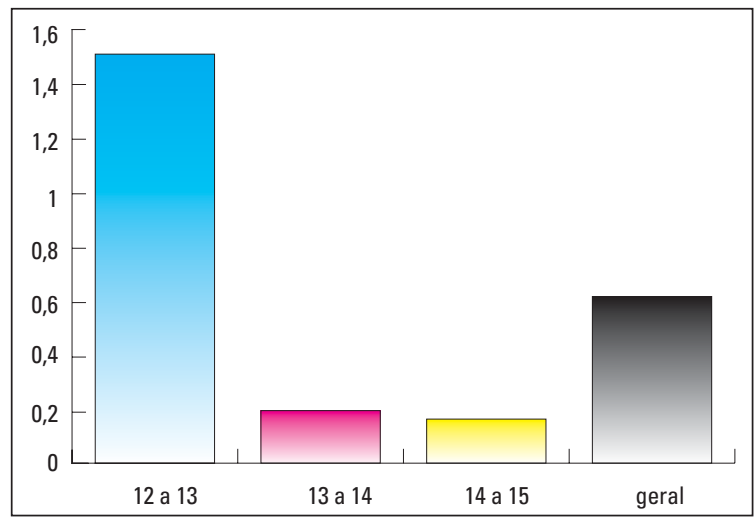

GRÁFICO 25 - Médias para o plano palatino/plano horizontal de Frankfurt.

dido entre $57^{\circ}$ e $63^{\circ}$.

Quando avaliada por idade, entre 12 e 13 anos a média foi de $56,04^{\circ} \pm 4,36^{\circ} ; 54,48^{\circ} \pm 4,10^{\circ}$ na faixa de 13 a 14 anos e $56,34^{\circ} \pm 4,19^{\circ}$ entre 14 e 15 anos.

Ao compararmos com as medidas encontradas por Ricketts et al..$^{33}$ de $60^{\circ} \pm 3^{\circ}$, não houve variação principalmente na média de idade de 12 a 13 anos e 14 a 15 anos.

\section{Campo VI - estruturas internas}

Fator 27 - deflexão craniana

Analisando a tabela 27, o resultado mostrou, com 95\% de probabilidade, que esta medida está contida entre $20^{\circ}$ e $35^{\circ}$ com uma média de $25,87^{\circ} \pm 2,72^{\circ}$. Verifica-se que entre 12 e 13 anos o valor foi de $25,86^{\circ} \pm 2,89^{\circ} ; 25,6^{\circ} \pm 3,07^{\circ}$ entre 13 e 14 anos e $26,16^{\circ} \pm 2,19^{\circ}$ entre 14 e 15 anos (Tab. 27). Esses valores estão diminuídos em relação ao padrão estabelecido por Ricketts et $\mathrm{al}^{33}$, que foi 
Tabela 26 - Altura facial total segundo a idade (graus).

\begin{tabular}{cccccccc}
\hline $\begin{array}{c}\text { idade } \\
\text { (anos) }\end{array}$ & freq. & média & d.c. & mínimo & máximo & I. inf. & I. sup. \\
\hline 12 a 13 & 25 & 56,04 & 4,36 & 48,00 & 67,00 & 54,24 & 57,84 \\
13 a 14 & 25 & 54,48 & 4,10 & 47,00 & 63,00 & 52,79 & 56,17 \\
14 a 15 & 25 & 56,34 & 4,19 & 49,00 & 67,00 & 54,61 & 58,07 \\
geral & 75 & 55,62 & 4,24 & 47,00 & 67,00 & 54,64 & 56,60 \\
\hline
\end{tabular}

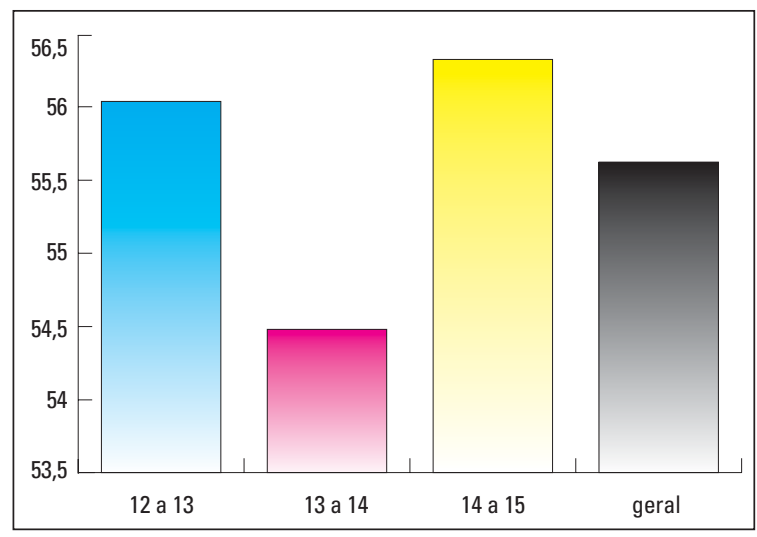

GRÁFICO 26 - Médias para a altura facial total.

de $27^{\circ} \pm 3^{\circ}$. A diminuição dessa medida significa: 1) tendência a se tornar mais paralelo o plano horizontal de Frankfurt em relação a básio-násio; 2) uma tendência mais horizontal do terço médio da face; 3) uma tendência a um posicionamento mais posterior da mandíbula.

\section{Fator 28 - comprimento craniano anterior}

Na tabela 28, observa-se que as idades de 13 a 14 anos e 14 a 15 anos possuem fatores em comum, o que não ocorre na idade de 12 a 13 anos. Com 95\% de probabilidade, o comprimento craniano anterior está entre $52,50 \mathrm{~mm}$ e $71 \mathrm{~mm}$, com um normal clínico de $59,53 \mathrm{~mm}$ e desvio clínico de $\pm 3,9 \mathrm{~mm}$. Com a idade de 12 a 13 anos apresentou-se um valor de $57,46 \mathrm{~mm} \pm 2,74 \mathrm{~mm} ; 60,74 \mathrm{~mm} \pm 4,09 \mathrm{~mm}$ aos 13 a 14 anos e $60,80 \mathrm{~mm} \pm 3,97 \mathrm{~mm}$ entre $14 \mathrm{e}$ 15 anos (Tab. 28). A média estabelecida por Ricketts et al..$^{33}$ apresentou um valor de $58,2 \mathrm{~mm}$ aos 12 anos e 6 meses; $59 \mathrm{~mm}$ aos 13 anos e 6 meses
Tabela 27 - Deflexão craniana segundo a idade (graus).

\begin{tabular}{cccccccc}
\hline $\begin{array}{c}\text { idade } \\
\text { (anos) }\end{array}$ & freq. & média & d. c. & mínimo & máximo & I. inf. & I. sup. \\
\hline 12 a 13 & 25 & 25,86 & 2,89 & 20,00 & 32,50 & 24,67 & 27,05 \\
13 a 14 & 25 & 25,60 & 3,07 & 21,50 & 35,00 & 24,33 & 26,87 \\
14 a 15 & 25 & 26,16 & 2,19 & 22,00 & 30,00 & 25,26 & 27,06 \\
geral & 75 & 25,87 & 2,72 & 20,00 & 35,00 & 25,25 & 26,50 \\
\hline
\end{tabular}

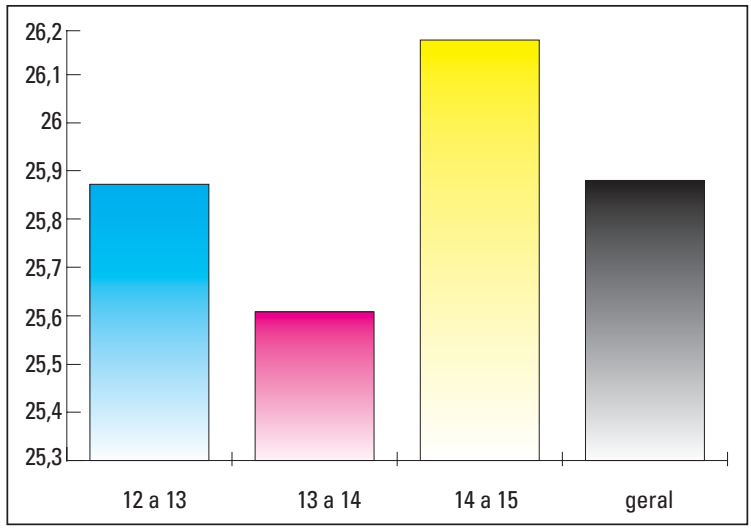

GRÁFICO 27 - Médias para a deflexão craniana.

Tabela 28 - Estatísticas para o comprimento craniano anterior segundo a idade $(\mathrm{mm})$.

\begin{tabular}{cccccccc}
\hline $\begin{array}{c}\text { idade } \\
\text { (anos) }\end{array}$ & freq. & média & d.c. & mínimo & máximo & I. inf. & I. sup. \\
\hline 12 a 13 & 25 & 57,46 & 2,74 & 52,52 & 63,00 & 56,33 & 58,59 \\
13 a 14 & 25 & 60,74 & 4,09 & 52,50 & 69,50 & 58,65 & 62,03 \\
14 a 15 & 25 & 60,80 & 3,97 & 53,50 & 71,00 & 59,16 & 62,44 \\
geral & 75 & 59,53 & 3,90 & 52,50 & 71,00 & 58,64 & 60,43 \\
\hline
\end{tabular}

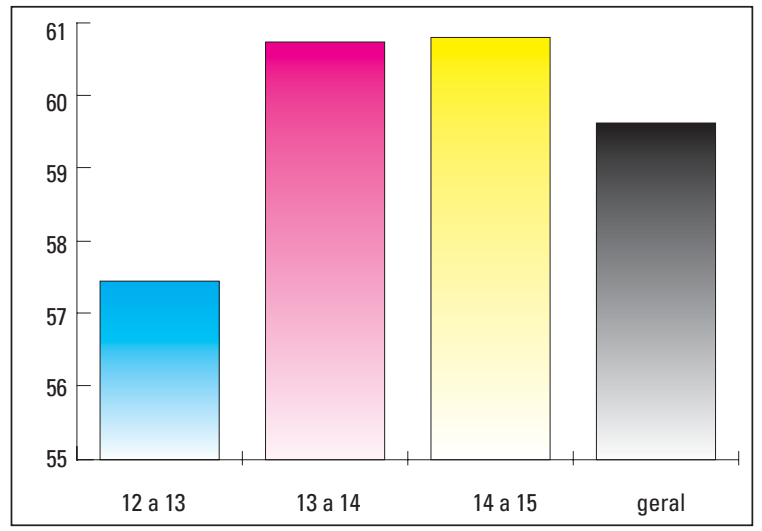

GRÁFICO 28 - Médias para o comprimento craniano anterior. 
Tabela 29 - Altura facial posterior segundo a idade (mm).

\begin{tabular}{cccccccc}
\hline $\begin{array}{c}\text { idade } \\
\text { (anos) }\end{array}$ & freq. & média & d. c. & mínimo & máximo & I. inf. & I. sup. \\
\hline 12 a 13 & 25 & 63,08 & 4,62 & 54,50 & 75,00 & 61,27 & 64,99 \\
13 a 14 & 25 & 66,96 & 5,42 & 54,00 & 79,50 & 64,72 & 69,20 \\
14 a 15 & 25 & 68,14 & 5,30 & 58,00 & 79,00 & 65,95 & 70,33 \\
geral & 75 & 66,06 & 5,50 & 54,00 & 79,50 & 64,79 & 67,33 \\
\hline
\end{tabular}

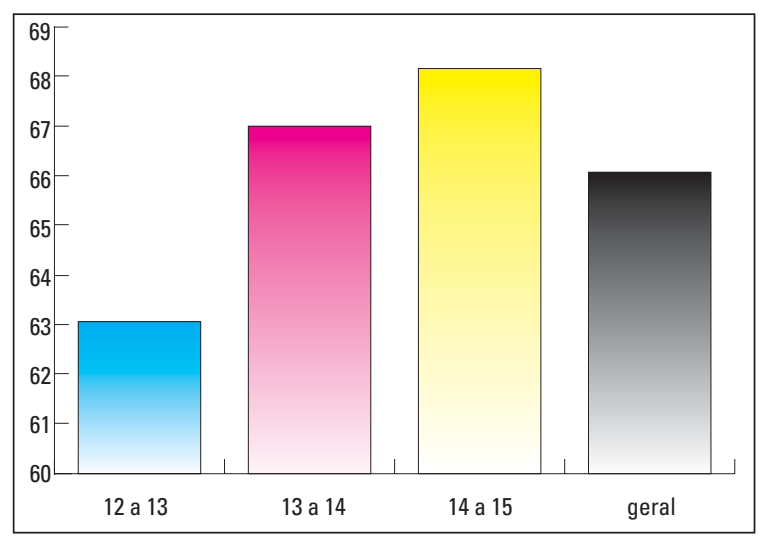

GRÁFICO 29 - Médias para a altura facial posterior.

e $59 \mathrm{~mm}$ aos 14 anos e 6 meses. Na idade entre 12 anos e 13 anos constatou-se uma média menor em relação à de Ricketts et $\mathrm{al} \cdot .^{33}$, significando uma base craniana anterior menor, o que indica uma leve Classe III e entre 13 anos e 14 anos e 14 e 15 anos ao contrário, a medida comprimento craniano anterior está aumentada, mostrando uma tendência a uma base craniana de má oclusão Classe II de Angle.

\section{Fator 29 - altura facial posterior}

Essa medida apresenta um intervalo de confiança, em nível de 95\%, compreendido entre $54 \mathrm{~mm}$ e $79,5 \mathrm{~mm}$, com uma média de $66,06 \mathrm{~mm} \pm 5,5 \mathrm{~mm}$. Para a idade entre 12 e 13 anos, a altura facial posterior apresentou um valor de $63,08 \mathrm{~mm} \pm 4,62 \mathrm{~mm} ; 66,96 \mathrm{~mm} \pm 5,42 \mathrm{~mm}$ entre 13 e 14 anos e $68,14 \mathrm{~mm} \pm 5,3 \mathrm{~mm}$ entre 14 e 15 anos (Tab. 29). De acordo com Ricketts et al. ${ }^{33}$,
Tabela 30 - Posição do ramo da mandíbula segundo a idade (graus).

\begin{tabular}{cccccccc}
\hline $\begin{array}{c}\text { idade } \\
\text { (anos) }\end{array}$ & freq. & média & d. c. & mínimo & máximo & I. inf. & I. sup. \\
\hline 12 a 13 & 25 & 72,00 & 2,78 & 66,00 & 78,50 & 70,85 & 73,15 \\
13 a 14 & 25 & 73,38 & 3,59 & 66,50 & 80,00 & 71,90 & 74,86 \\
14 a 15 & 25 & 72,78 & 2,59 & 66,50 & 77,50 & 71,71 & 73,85 \\
geral & 75 & 72,72 & 3,03 & 66,00 & 80,00 & 72,02 & 73,42 \\
\hline
\end{tabular}

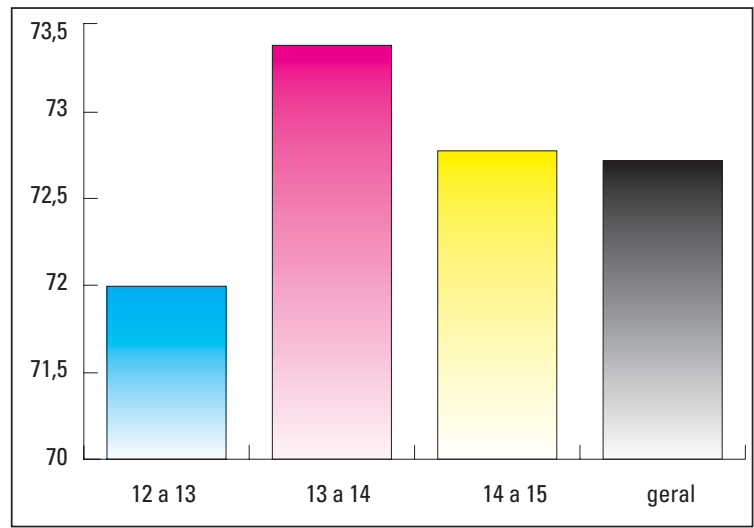

GRÁFICO 30 - Médias para a posição do ramo da mandíbula.

aos 8 anos e 6 meses, o fator altura facial posterior deveria medir $55 \mathrm{~mm} \pm 3 \mathrm{~mm}$. Na fase de crescimento, essa medida aumentou $0,8 \mathrm{~mm}$ por ano, chegando aos 12 anos e 6 meses com o valor de $58,2 \mathrm{~mm} ; 59 \mathrm{~mm}$ aos 13 anos e 6 meses e $59,8 \mathrm{~mm}$ aos 14 anos e 6 meses. Verifica-se que os valores da altura facial posterior estudada são mais altos que os da amostra de Ricketts et al. ${ }^{33}$

\section{Fator 30 - posição do ramo da mandíbula}

Esse fator mostra o posicionamento do ramo da mandíbula e está compreendido entre $66^{\circ}$ e $80^{\circ}$, com uma média de $72,72^{\circ} \pm 3,03^{\circ}$. Assim é que, entre 12 e 13 anos a amostra estudada apresentou um valor de $72^{\circ} \pm 2,78^{\circ} ; 73,38^{\circ} \pm 3,59^{\circ}$ entre 13 e 14 anos e $72,78^{\circ} \pm 2,59^{\circ}$ entre 14 e 15 anos (Tab. 30), diferindo dos valores de Ricketts et al. ${ }^{33}$ que apresentou um normal clínico de $76^{\circ} \pm 3^{\circ}$. Verificaram-se, nas três faixas etárias, valores inferiores 
Tabela 31 - Localização da posição do pório segundo a idade $(\mathrm{mm})$.

\begin{tabular}{cccccccc}
\hline $\begin{array}{c}\text { idade } \\
\text { (anos) }\end{array}$ & freq. & média & d.c. & mínimo & máximo & I. inf. & I. sup. \\
\hline 12 a 13 & 25 & $-42,40$ & 2,65 & $-48,00$ & $-36,00$ & $-43,49$ & $-41,31$ \\
13 a 14 & 25 & $-42,36$ & 2,96 & $-50,00$ & $-36,00$ & $-43,58$ & $-41,14$ \\
14 a 15 & 25 & $-43,26$ & 3,50 & $-51,00$ & $-38,00$ & $-44,70$ & $-41,82$ \\
geral & 75 & $-42,67$ & 3,04 & $-51,00$ & $-36,00$ & $-43,37$ & $-41,97$ \\
\hline
\end{tabular}

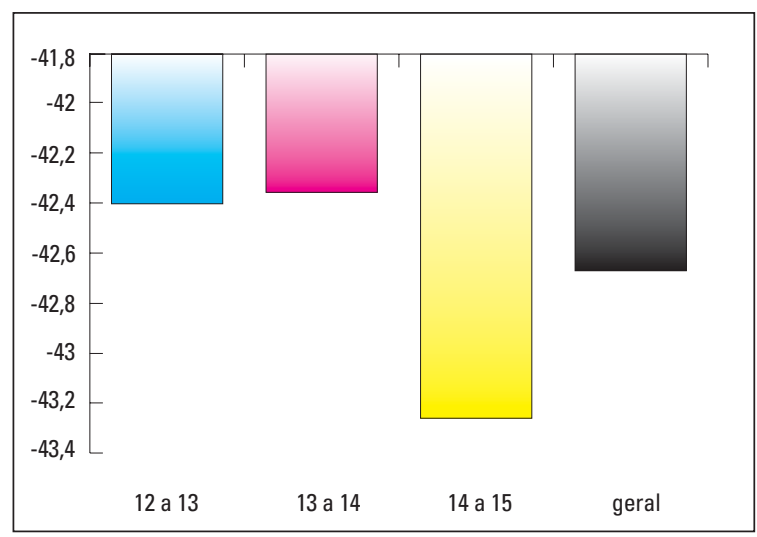

GRÁFICO 31 - Médias para a posição do pório.

comparados com Ricketts et al..$^{33}$ significando que o ramo da mandíbula se posiciona mais posteriormente, principalmente aos 12 anos e 6 meses e aos 14 anos e 6 meses, sendo a diferença maior que o desvio clínico.

\section{Fator 31 - posição do pório}

A localização do pório na amostra estudada está contida entre $-51 \mathrm{~mm}$ e $-36 \mathrm{~mm}$, com uma média de $-42,67 \mathrm{~mm} \pm 3,04 \mathrm{~mm}$ (Tab. 31). Segundo Ricketts et al. ${ }^{33}$ este fator aumenta $0,5 \mathrm{~mm}$ por ano com o crescimento, tendo aos 9 anos o valor médio de -39mm; -40,75mm aos 12 anos e 6 meses; $-41,25 \mathrm{~mm}$ aos 13 anos e 6 meses e $-41,75 \mathrm{~mm}$ aos 14 anos e 6 meses.

Os valores encontrados nesse estudo são maiores que os valores encontrados por Ricketts et al. ${ }^{33}$

Assim é que entre 12 e 13 anos o valor encontra-
Tabela 32 - Arco mandibular segundo a idade (graus).

\begin{tabular}{cccccccc}
\hline $\begin{array}{c}\text { idade } \\
\text { (anos) }\end{array}$ & freq. & média & d.c. & mínimo & máximo & l. inf. & l. sup. \\
\hline 12 a 13 & 25 & 29,80 & 4,40 & 20,00 & 38,00 & 27,98 & 31,62 \\
13 a 14 & 25 & 31,98 & 4,15 & 23,50 & 40,50 & 30,27 & 33,69 \\
14 a 15 & 25 & 34,02 & 9,77 & 23,00 & 77,00 & 29,99 & 38,05 \\
geral & 75 & 31,93 & 6,77 & 20,00 & 77,00 & 30,38 & 33,49 \\
\hline
\end{tabular}

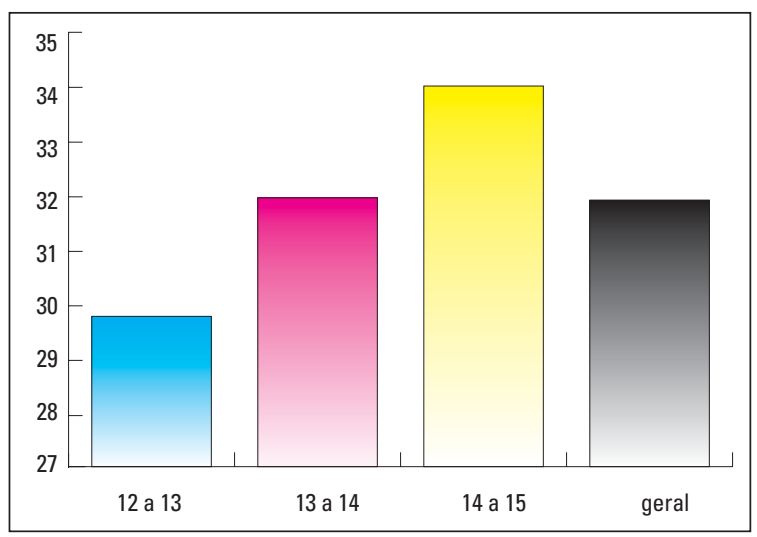

GRÁFICO 32 - Médias para 0 arco mandibular.

do foi de $-42,4 \mathrm{~mm} \pm 2,65 \mathrm{~mm} ;-42,36 \mathrm{~mm} \pm 2,96 \mathrm{~mm}$ entre 13 e 14 anos e $-43,26 \mathrm{~mm} \pm 3,50 \mathrm{~mm}$ entre 14 e 15 anos. Isto posto, observa-se que a amostra estudada apresentou uma posição mais posterior da articulação temporomandibular do plano Pt.V., em relação à média da amostra de Ricketts et al. ${ }^{33}$, significando uma tendência para uma posição de Classe II de Angle.

\section{Fator 32 - arco mandibular}

$\mathrm{Na}$ tabela 32, com 95\% de probabilidade de acerto, a medida arco mandibular está contida entre $20^{\circ}$ e $77^{\circ}$ com uma média de $31,93^{\circ} \pm 6,77^{\circ}$. Observa-se que entre 12 e 13 anos o valor foi de $29,80^{\circ} \pm 4,40^{\circ} ; 31,98^{\circ} \pm 4,15^{\circ}$ entre 13 e 14 anos e $34,02^{\circ} \pm 9,77^{\circ}$ entre 14 e 15 anos. Quando comparado com Ricketts et al. ${ }^{33}$, que mostrou que aos 8 anos e 6 meses o valor médio é de $26^{\circ}$ com desvio clínico de $\pm 4^{\circ}$, aumentando $0,5^{\circ}$ por ano e apre- 
sentando $28^{\circ}$ aos 12 anos e 6 meses; $28,5^{\circ}$ aos 13 anos e 6 meses e $29^{\circ}$ aos 14 anos e 6 meses. Os valores das médias da medida estudada são bem maiores que as médias de Ricketts et $\mathrm{al}^{33}$, significando uma estrutura da mandíbula com tendência de crescimento mais horizontal, principalmente aos 14 anos e 6 meses, cujo valor da média, comparado com o da média da amostra de Ricketts et al. ${ }^{33}$, é superior à média estabelecida.

\section{Fator 33 - comprimento do corpo mandibular}

É de grande importância esse fator que avalia se o prognatismo ou retrognatismo é devido ao comprimento da mandíbula. No presente estudo o limite inferior e superior estão entre $64,50 \mathrm{~mm}$ e $84,00 \mathrm{~m}$ com uma média de $74,03 \mathrm{~mm} \pm 4,18 \mathrm{~mm}$. Para a idade entre 12 e 13 anos o valor da medida do comprimento do corpo mandibular foi de $71,90 \mathrm{~mm} \pm 3,45 \mathrm{~mm} ; 74,40 \mathrm{~mm} \pm 3,93 \mathrm{~mm}$ entre 13 e 14 anos e $75,8 \mathrm{~mm} \pm 4,28 \mathrm{~mm}$ entre 14 e 15 anos

Tabela 33 - Comprimento do corpo mandibular segundo a idade $(\mathrm{mm})$.

\begin{tabular}{cccccccc}
\hline $\begin{array}{c}\text { idade } \\
\text { (anos) }\end{array}$ & freq. & média & d. c. & mínimo & máximo & I. inf. & I. sup. \\
\hline 12 a 13 & 25 & 71,90 & 3,45 & 64,50 & 76,50 & 70,48 & 73,32 \\
13 a 14 & 25 & 74,40 & 3,93 & 64,50 & 81,50 & 72,78 & 76,02 \\
14 a 15 & 25 & 75,80 & 4,28 & 68,00 & 84,00 & 74,03 & 77,57 \\
geral & 75 & 74,03 & 4,18 & 64,50 & 84,00 & 73,07 & 74,99 \\
\hline
\end{tabular}

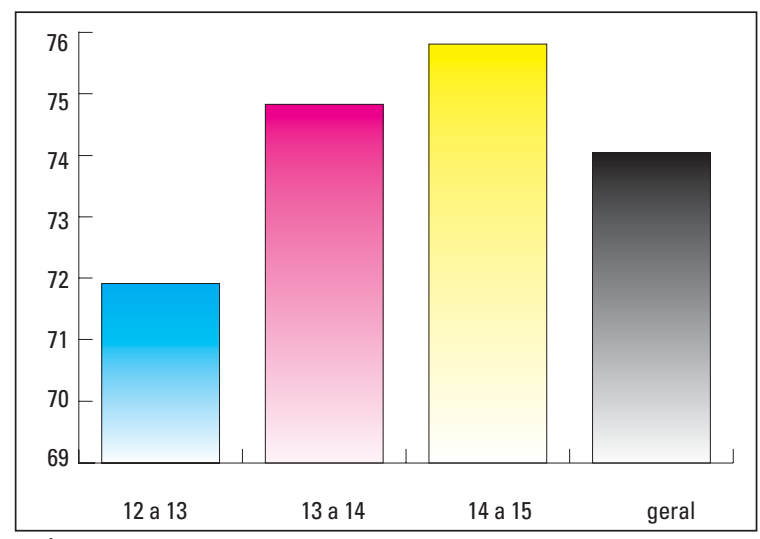

GRÁFICO 33 - Médias para o comprimento do corpo mandibular.
(Tab. 33). Essas medidas diferem da encontrada por Ricketts et al..$^{33}$, que observaram $65 \mathrm{~mm}$ aos 8 anos e 6 meses, com um aumento de crescimento de $1,6 \mathrm{~mm}$ por ano e um desvio clínico de $\pm 2,7 \mathrm{~mm}$; tendo $71,4 \mathrm{~mm}$ aos 12 anos e 6 meses; $73 \mathrm{~mm}$ aos 13 anos e 6 meses e $74,6 \mathrm{~mm}$ aos 14 anos e 6 meses.

Quando comparados os valores da amostra com os de Ricketts et al. ${ }^{33}$ os valores de cada idade foram maiores, significando um comprimento maior do corpo mandibular.

\section{CONCLUSÃO}

É lícito concluir que, na amostra estudada, os valores encontrados nos campos I, II, III, IV, V e VI (presentes nos quadros 1 a 6), quando comparados aos valores encontrados por Ricketts et al. ${ }^{33}$ :

No campo I - problemas dentários - os molares e caninos superiores da amostra estudada posicionaram-se mais anteriormente em relação ao seu antagônico inferior, tendo como possível conseqüência um aumento da sobressaliência (overjet), sobremordida (overbite), maior extrusão dos incisivos inferiores e uma pequena diminuição do ângulo interincisivos.

No campo II - problemas esqueléticos - posicionamento mais anterior da maxila em relação à mandíbula dos indivíduos da amostra estudada e uma diminuição da medida altura vertical anterior de $1,89 \mathrm{~mm}$ com desvio clínico de $\pm 1,94 \mathrm{~mm}$. A altura facial inferior apresentou um valor médio de $42,51^{\circ}$ e um desvio clínico de $\pm 2,65^{\circ}$.

No campo III - problemas dentoesqueléticos - os $1^{\text {os }}$ molares superiores posicionaram-se mais anteriormente em relação ao vertical pterigóide. Os incisivos superiores e inferiores apresentaramse mais protruídos, com maior inclinação anterior dos incisivos inferiores e maior verticalização dos incisivos superiores; o plano oclusal apresentou-se passando acima da posição estabelecida por Ricketts em relação ao ponto Xi e com inclinação menor em relação ao eixo do corpo mandibular.

No campo IV - problemas estéticos - o lábio 
Quadro 1 - Campo I (Problemas dentários).

\begin{tabular}{lllll}
\hline & $\begin{array}{c}\text { valores de Ricketts } \\
\text { (13a. } 6 \mathrm{~m} .)\end{array}$ & amostra estudada \\
\hline $\begin{array}{l}\text { Fator 1 } \\
\text { relação molar }\end{array}$ & $-3 \mathrm{~mm}$ & $( \pm 3 \mathrm{~mm})$ & $-1,96 \mathrm{~mm}$ & $( \pm 0,96 \mathrm{~mm})$ \\
\hline $\begin{array}{l}\text { Fator 2 - relação } \\
\text { dos caninos }\end{array}$ & $-2 \mathrm{~mm}$ & $( \pm 3 \mathrm{~mm})$ & $-1,58 \mathrm{~mm}$ & $( \pm 0,43 \mathrm{~mm})$ \\
\hline $\begin{array}{l}\text { Fator 3 } \\
\text { trespasse } \\
\text { horizontal }\end{array}$ & $2,5 \mathrm{~mm}$ & $( \pm 2,5 \mathrm{~mm})$ & $3,19 \mathrm{~mm}$ & $( \pm 0,59 \mathrm{~mm})$ \\
\hline $\begin{array}{l}\text { Fator } 4 \\
\text { trespasse } \\
\text { vertical }\end{array}$ & $2,5 \mathrm{~mm}$ & $( \pm 2 \mathrm{~mm})$ & $2,85 \mathrm{~mm}$ & $( \pm 0,74 \mathrm{~mm})$ \\
\hline $\begin{array}{l}\text { Fator } 5 \\
\text { extrusão do } \\
\text { incisivo inferior }\end{array}$ & $1,25 \mathrm{~mm}$ & $( \pm 2 \mathrm{~mm})$ & $2,33 \mathrm{~mm}$ & $( \pm 1,08 \mathrm{~mm})$ \\
\hline $\begin{array}{l}\text { Fator 6 } \text { ângulo } \\
\text { interincisivos }\end{array}$ & $130^{\circ}$ & $\left( \pm 10^{\circ}\right)$ & $128,59^{\circ}$ & $\left( \pm 5,6^{\circ}\right)$ \\
\hline
\end{tabular}

Quadro 2 - Campo II (Problemas esqueléticos).

\begin{tabular}{lcrrr}
\hline & $\begin{array}{c}\text { valores de Ricketts } \\
\text { (13a. 6m.) }\end{array}$ & amostra estudada \\
\hline $\begin{array}{l}\text { Fator } 7 \text { - convexidade } \\
\text { do ponto A }\end{array}$ & $1 \mathrm{~mm}$ & $( \pm 2 \mathrm{~mm})$ & $1,89 \mathrm{~mm}$ & $( \pm 1,94 \mathrm{~mm})$ \\
\hline $\begin{array}{l}\text { Fator } 8 \text { - altura facial } \\
\text { inferior }\end{array}$ & $45^{\circ}$ & $\left( \pm 4^{\circ}\right)$ & $42,51^{\circ}$ & $\left( \pm 2,65^{\circ}\right)$ \\
\hline
\end{tabular}

Quadro 3 - Campo III (Problemas dentoesqueléticos).

\begin{tabular}{|c|c|c|c|c|}
\hline \multirow[b]{2}{*}{$\begin{array}{l}\text { Fator } 9 \text { - posição do } 1^{\circ} \\
\text { molar sup. (6-PTV) }\end{array}$} & \multicolumn{2}{|c|}{$\begin{array}{l}\text { valores de Ricketts } \\
(13 \mathrm{a} .6 \mathrm{~m} .)\end{array}$} & \multicolumn{2}{|c|}{ amostra estudada } \\
\hline & $16,5 \mathrm{~mm}$ & $( \pm 3 \mathrm{~mm})$ & $18,18 \mathrm{~mm}$ & $( \pm 3,56 \mathrm{~mm})$ \\
\hline $\begin{array}{l}\text { Fator } 10 \text { - protrusão do } \\
\text { inc. central inf. }\end{array}$ & $1 \mathrm{~mm}$ & $( \pm 2 \mathrm{~mm})$ & $2,21 \mathrm{~mm}$ & $( \pm 1,76 \mathrm{~mm})$ \\
\hline $\begin{array}{l}\text { Fator } 11 \text { - protrusão do } \\
\text { inc. central sup. }\end{array}$ & $3,5 \mathrm{~mm}$ & $( \pm 5 \mathrm{~mm})$ & $5,31 \mathrm{~mm}$ & $( \pm 1,89 \mathrm{~mm})$ \\
\hline $\begin{array}{l}\text { Fator } 12 \text { - inclinação do } \\
\text { inc. central inf. }\end{array}$ & $22^{\circ}$ & $\left( \pm 4^{\circ}\right)$ & $24,09^{\circ}$ & $\left( \pm 3,26^{\circ}\right)$ \\
\hline $\begin{array}{l}\text { Fator } 13 \text { - inclinação do } \\
\text { inc. central sup. }\end{array}$ & $28^{\circ}$ & $\left( \pm 4^{\circ}\right)$ & $27,75^{\circ}$ & $\left( \pm 5,08^{\circ}\right)$ \\
\hline $\begin{array}{l}\text { Fator } 14 \text { - plano oclusal } \\
\text { ao ramo Xi }\end{array}$ & $-2 \mathrm{~mm}$ & $( \pm 3 \mathrm{~mm})$ & $-0,85 \mathrm{~mm}$ & $( \pm 2,60 \mathrm{~mm})$ \\
\hline $\begin{array}{l}\text { Fator } 15 \text { - inclinação do } \\
\text { plano oclusal }\end{array}$ & $24,75^{\circ}$ & $\left( \pm 8^{\circ}\right)$ & $21,04^{\circ}$ & $\left.\pm 8,64^{\circ}\right)$ \\
\hline
\end{tabular}

Quadro 4 - Campo IV (Problemas estéticos).

\begin{tabular}{lcccc}
\hline & \multicolumn{2}{c}{$\begin{array}{c}\text { valores de Ricketts } \\
(13 a .6 m .)\end{array}$} & amostra estudada \\
\hline $\begin{array}{l}\text { Fator 16 } \\
\text { posição labial }\end{array}$ & $-3 \mathrm{~mm}$ & $( \pm 2 \mathrm{~mm})$ & $-0,95 \mathrm{~mm}$ & $( \pm 2,37 \mathrm{~mm})$ \\
\hline $\begin{array}{l}\text { Fator 17 - comp. } \\
\text { do lábio superior }\end{array}$ & $24 \mathrm{~mm}$ & $( \pm 2 \mathrm{~mm})$ & $26,74 \mathrm{~mm}$ & $( \pm 2,40 \mathrm{~mm})$ \\
\hline $\begin{array}{l}\text { Fator 18 - ponto } \\
\begin{array}{l}\text { união interlabial- } \\
\text { plano oclusal }\end{array}\end{array}$ & $-4 \mathrm{~mm}$ & $( \pm 2 \mathrm{~mm})$ & $-3,46 \mathrm{~mm}$ & $( \pm 2,31 \mathrm{~mm})$ \\
\hline
\end{tabular}

Quadro 5 - Campo V (Relação craniofacial).

\begin{tabular}{lcccc}
\hline & $\begin{array}{c}\text { valores de Ricketts } \\
(13 a .6 \mathrm{~m} .)\end{array}$ & \multicolumn{2}{c}{ amostra estudada } \\
\hline $\begin{array}{l}\text { Fator 19 } \\
\text { profundidade facial }\end{array}$ & $88,5^{\circ}$ & $\left( \pm 3^{\circ}\right)$ & $89,23^{\circ}$ & $\left( \pm 3,25^{\circ}\right)$ \\
\hline $\begin{array}{l}\text { Fator 20 - eixo facial } \\
90^{\circ}\end{array}$ & $\left( \pm 3,5^{\circ}\right)$ & $93,11^{\circ}$ & $\left( \pm 3,18^{\circ}\right)$ \\
\hline $\begin{array}{l}\text { Fator 21 - cone facial } \\
68^{\circ}\end{array}$ & $\left( \pm 3,5^{\circ}\right)$ & $68,90^{\circ}$ & $\left( \pm 2,90^{\circ}\right)$ \\
\hline $\begin{array}{l}\text { Fator 22 } \\
\text { plano mandibular }\end{array}$ & $24,65^{\circ}$ & $\left( \pm 4^{\circ}\right)$ & $23,42^{\circ}$ & $\left( \pm 4,70^{\circ}\right)$ \\
\hline $\begin{array}{l}\text { Fator 23 } \\
\text { profundidade maxilar }\end{array}$ & $90^{\circ}$ & $\left( \pm 3^{\circ}\right)$ & $91,09^{\circ}$ & $\left( \pm 3,37^{\circ}\right)$ \\
\hline $\begin{array}{l}\text { Fator 24 } \\
\text { altura maxilar }\end{array}$ & $54,8^{\circ}$ & $\left( \pm 3^{\circ}\right)$ & $56,22^{\circ}$ & $\left( \pm 3,54^{\circ}\right)$ \\
\hline $\begin{array}{l}\text { Fator 25 - plano } \\
\text { palatino/plano } \\
\text { horizontal Frankfurt }\end{array}$ & $1^{\circ}$ & $\left( \pm 3,5^{\circ}\right)$ & $0,63^{\circ}$ & $\left( \pm 3,06^{\circ}\right)$ \\
\hline $\begin{array}{l}\text { Fator 26 } \\
\text { altura facial total }\end{array}$ & $60^{\circ}$ & $\left( \pm 3^{\circ}\right)$ & $55,62^{\circ}$ & $\left( \pm 4,24^{\circ}\right)$ \\
\hline
\end{tabular}

Quadro 16 - Campo VI (Estruturas internas).

\begin{tabular}{lcccc}
\hline & $\begin{array}{c}\text { valores de Ricketts } \\
\text { (13a. 6m.) }\end{array}$ & amostra estudada \\
\hline $\begin{array}{l}\text { Fator 27 } \\
\text { deflexão } \\
\text { craniana }\end{array}$ & $27^{\circ}$ & $\left( \pm 3^{\circ}\right)$ & $25,87^{\circ}$ & $\left( \pm 2,72^{\circ}\right)$ \\
\hline $\begin{array}{l}\text { Fator } 28 \\
\text { comp. craniano } \\
\text { anterior }\end{array}$ & $59 \mathrm{~mm}$ & $( \pm 2,5 \mathrm{~mm})$ & $59,53 \mathrm{~mm}$ & $( \pm 3,90 \mathrm{~mm})$ \\
\hline $\begin{array}{l}\text { Fator 29 - altura } \\
\text { facial posterior }\end{array}$ & $59 \mathrm{~mm}$ & $( \pm 3,3 \mathrm{~mm})$ & $66,06 \mathrm{~mm}$ & $( \pm 5,50 \mathrm{~mm})$ \\
\hline $\begin{array}{l}\text { Fator 30 } \\
\text { posição do ramo } \\
\text { mandibular }\end{array}$ & $76^{\circ}$ & $\left( \pm 3^{\circ}\right)$ & $72,72^{\circ}$ & $\left( \pm 3,03^{\circ}\right)$ \\
\hline $\begin{array}{l}\text { Fator 31 } \\
\text { posição do pório }\end{array}$ & $-41,25 \mathrm{~mm}$ & $( \pm 2,2 \mathrm{~mm})$ & $-42,67 \mathrm{~mm}$ & $( \pm 3,04 \mathrm{~mm})$ \\
\hline $\begin{array}{l}\text { Fator } 32 \text { - arco } \\
\text { mandibular }\end{array}$ & $28,3^{\circ}$ & $\left( \pm 4^{\circ}\right)$ & $31,93^{\circ}$ & $\left( \pm 3,77^{\circ}\right)$ \\
\hline $\begin{array}{l}\text { Fator 33 } \\
\text { comp. do corpo } \\
\text { mandibular }\end{array}$ & $73 \mathrm{~mm}$ & $( \pm 2,7 \mathrm{~mm})$ & $74,03 \mathrm{~mm}$ & $( \pm 4,18 \mathrm{~mm})$ \\
\hline & & & \\
\hline
\end{tabular}


inferior posicionou-se mais anteriormente em relação à linha do plano estético "E" de Ricketts e com o ponto de união do lábio superior com o inferior suavemente inferior em relação ao plano oclusal preconizado.

No campo V - relação craniofacial - a mandíbula apresentou-se com uma ligeira posição anterior e com rotação anti-horária (tendência ao crescimento mais horizontal aumentado). A maxila, também, com um posicionamento mais anterior, embora sem significância estatística em relação à base craniana; um aumento da dimensão vertical anterior da maxila com inclinação diminuída do plano palatal.

No campo VI - estruturas internas - a amostra estudada revelou um posicionamento mais poste- rior do ramo da mandíbula, com uma forte tendência ao crescimento horizontal da mandíbula na sua própria estrutura interna, através do fator arco mandibular.

Uma grande maioria dos 33 fatores dos 6 campos da cefalometria proposta por Rickets et al. ${ }^{33}$ difere das medidas encontradas na amostra, portanto não se recomenda adaptar aos brasileiros, que embora leucodermas têm uma maior miscigenação de raças.

Desta forma, para elaboração do diagnóstico e planejamento do tratamento ortodôntico, julgamos oportuno adotar medidas específicas para brasileiros.

Enviado em: junho de 2005 Revisado e aceito: agosto de 2005

\title{
Ricketts cephalometric patterns applied to Brazilians individuals with excellent occlusion
}

\begin{abstract}
Aim: to analyse the 33 cefalometric factors included in the six fields of Rickets analysis in a sample of Brazilians, and compare these values with cefalometric standards for North American individuals. Methods: after having been chosen 75 Brazilian leucoderms, with age between 12 and 15, with better aesthetic aspects, balance, face harmony and mainly with excellent dental occlusion, results of a search in 14,000 students attending elementary and high school, in the area of Marilia, Assis and Ourinhos/SP, all of the 33 factors of cephalometric measures of the 75 individuals were compared with the results obtained for Ricketts, in a sample of american leucoderms. Results and Conclusion: 1) under skeletal level, the maxilla presented a behavior according to the author's proclaimed patterns. The jaw showed a more horizontal development trend in its branch; 2) under tooth structure level, the lower incisors located more foregoing and with bigger bending. The horizontal, vertical trespassing and the lower incisors extrusion presented themselves perceptibly increased, probably due to the jaw horizontal development trend; 3) related to "E" 'Ricketts' aesthetic planning, the lower lip showed a more anterior location related to the author's claimed pattern; 4) The clinical deviations, in the most part of the factors, were very bigger in Brazilians than in Americans, probably related to the bigger miscegenation in the Brazilian leucoderms.
\end{abstract}

Key words: Cephalometric. Analysis of Ricketts. Patterns in Brazilian.

\section{REFERÊNCIAS}

1. ALMEIDA, P. D.: VIGORITO J. W. Estudo comparativo entre os padrões cefalométrico-radiográficos de Steiner e de brasileiros, leucodermas, portadores de oclusão normal. Ortodontia, São Paulo, v. 21, p. 73-84, 1988

2. ANGLE, E. H. Classification of malocclusion. Dent Cosmos, Philadelphia, v. 41, no. 2, p. 248-264, Mar./Apr. 1899.
3. ARAÚJO, M. C. M. Contribuição ao estudo dos desvios ânteroposteriores da mandíbula, através das radiografias cefalométricas (nos casos de Classe I e Classe II de Angle) - Piracicaba. 1964. 123 f. Tese (Livre Docência)-Faculdade de Odontologia de Piracicaba, Universidade de Campinas, Piracicaba, 1964.

4. BISHARA, S. E. Longitudinal cephalometric standards from 5 years of age to adulthood. Am J Orthod, St. Louis, v. 79, no. 1, p. 35-44, Jan. 1981

5. BROADBENT, B. H. A new X-ray technique and its application to Orthodontia. Angle Orthod, Appleton, v. 1, no. 2, p. 45-66, Apr. 1931. 
6. CIVOLANI, M. I. Padrões cefalométricos de Tweed, Steiner Wylie e Downs aplicados a indivíduos brasileiros com oclusão normal. 1977. 73 f. Dissertação (Mestrado em Ortodontia)-Faculdade de Odontologia da Universidade de Campinas, Campinas, SP, 1977

7. COX, N. H.; LINDEN. F. P. G. M. Van der. Facial harmony. Am J Orthod, St. Louis, v. 60, no. 2, p. 175-183, Aug. 1971.

8. DOWNS, W. B. Variation in facial relationship: their significance in treatment and prognosis. Am J Orthod, St. Louis, v. 34, no. 10, p. $812-840$, Oct. 1948

$9 . \quad$ The role cephalometrics in orthodontic case analysis and diagnosis. Am J Orthod, St. Louis, v. 38, no. 3, p. 162-182, Mar. 1952.

10. GRESHAM, H. Cephalometric comparison of some skeletal and denture pattern components in two groups of children with acceptable occlusions. Angle Orthod, Appleton, v. 33, no. 2, p. 114-119, Apr. 1963.

11. GRESHAM, H.; BROWN, T.; BARRET, M. J. Skeletal and denture patterns in children from Yuendumu, Central Australia, and Melbourne. Aust Dent J, v. 10, no. 6, p. 462-468, Dec. 1965.

12. HIGLEY, L. B. Cephalometric standards for children of $4-8$ years of age. Am J Orthod, St. Louis, v. 40, no. 1, p. 51-59, Jan. 1954

13. HIRSCH, H.; HALL, S. R.; BACHAND, R. A cephalometric evaluation of 8-years old caucasians. Am J Orthod, St. Louis, v. 56 no. 2, p. 128-133, Aug. 1969.

14. HOFRATH, H. Techniques. In: Roentgenographic cefalometry. Philadelphia: College Offsef, 1957

15. INTERLANDI, S. Linha "I" na análise morfodiferencial para o diagnóstico. Rev Fac Odontol São Paulo, São Paulo, v. 9, n. 2, p. 289-310, jul./dez. 1971

16. KOWALSKI, C. J.; WALKER, G. F. The use of incisal angles in the Steiner's cephalometric analysis. Angle Orthod, Appleton, v. 42, no. 2, p. 87-95, Apr. 1972.

17. LANGLADE, M. Céphalométrie orthodontique. Paris: Bench 1976.

18. Diagnostic orthodontique. Paris: Bench 1981

19. MARTINS, D. R. Estudo comparativo dos valores cefalométricos das análises de Downs, Tweed, Steiner e Alabama, em adolescentes brasileiros leucodermas, de origem mediterrânea. 1979. 141f. Tese (Livre Docência)-Faculdade de Odontologia da Universidade de São Paulo, Bauru, 1979

20. MATOS, E. B. Análise de Tweed: individualização para uma comunidade de brasileiros. 1980. 72 f. Dissertação (Mestrado em Ortodontia)-Faculdade de Odontologia da Universidade Federal do Rio de Janeiro, Rio de Janeiro, 1980

21. PACINI, A. B. Roentgen ray anthropometry of the skull. J Radiol, Paris, v. 3, no. 6, p. 230-238, 1922

22. RAMANZINI, W. A. Análise cefalométrica das inclinações dentárias e suas respectivas bases ósseas em indivíduos dotados de oclusão normal e portadores de maloclusão classe II, divisão 1. 1981. 74 f. Dissertação (Mestrado em Ortodontia)-Faculdade de Odontologia da Universidade de Campinas, Piracicaba, 1981

23. RICKETTS, R. M. Planning treatment on the basis of the facial pattern and an estimate of its growth. Am J Orthod, St. Louis, v. 27 , no. 1,1957

$24 . \quad$ A foundation for cephalometric communication. Am J Orthod, St. Louis, v. 46, no. 5, p. 330-357, May 1960

$25 . \quad$ Cephalometric Synthesis. Am J Orthod, St. Louis, v. 46, no. 9, p. 647-673, Sept. 1960

. The Keystone Triad. I- Anatomy, phylogenetics and clinical references. Am J Orthod, St. Louis, v. 50, no. 4, p. 244 264,1964

$27 . \quad$ Esthetics enviroment and the law of lip relation. Am J Orthod, St. Louis, v. 54, no. 4, p. 272 - 289 Apr. 1968

28. Occlusion - the medium of dentistry. J Prosthet Dent, St. Louis, v. 1, no. 21, p. 39-60, Jan. 1969

$29 . \quad$ Analysis - The Interim. Angle Orthod, Appleton, v. 40 , no. 2 , p. $129-137$, Apr. 1970

30. An overview of computerized, cephalometrics. Am J Orthod, St. Louis, v. 61, no. 1, p. 1-28, Jan. 1972
31. New perspectives in orientation and their benefits to clinical Orthodontics - Part I. Angle Orthod, Appleton, v. 45, no. 4 , p. $238-248$, Oct. 1975

Perspectives in the clinical application of cefhalometrics - The first fifty years. Angle Orthod, Appleton, v. 51, no. 2, p. $115-150$, Apr. 1981.

33. RICKETTS, R. M. et al. Orthodontic diagnosis and planning. [USA]: Rock Mountain Orthod., 1982. v. 1

34. Orthodontic diagnosis and planning. [USA] . Rock Mountain Orthod., 1982. v. 2.

35. RINO NETO, J. Estudo cefalométrico radiográfico em crianças leucodermas brasileiras, portadoras de oclusão dentária excelente, na faixa etária dos sete aos nove anos de idade. 1990. 119 f. Dissertação (Mestrado em Ortodontia)-Faculdade de Odontologia da Universidade de São Paulo, São Paulo, 1990

36. RINO, W. Comportamento do incisivo superior no triângulo de Tweed 1992. 98 f. Tese (Doutorado em Ortodontia)-Faculdade de Odontologia da Universidade de Campinas, Piracicaba, 1992.

37. SCHAEFFER, A. Behavior of the axis of human incisor teeth during growth. Angle Orthod, Appleton, v. 19, no. 4, p. 254-275, Oct. 1949.

38. SIQUEIRA, V. C. V. Dentição mista. Estudo cefalométrico de estruturas crânio-faciais em indivíduos brasileiros, dotados de oclusão clinicamente excelente. 1989. 86 f. Dissertação (Mestrado)-Faculdade de Odontologia da Universidade de Campinas, Piracicaba, 1989.

39. STEINER, C. C. Cephalometrics for you and me. Am J Orthod St. Louis, v. 39 , no. 10 , p. 729-755, Oct. 1953

40. TWEED, C. H. The Frankfurt-mandibular plane angle in orthodontic diagnosis, classification, treatment planning and prognosis. Am J Orthod Oral Sugery, St. Louis, v. 32, no. 4, p. 175230, Apr. 1946

41. VION, P. E. Anatomia cefalométrica. 1. ed. São Paulo: Ed. Santos, 1994

\section{Endereço para correspondência}

Walter Rino

Av. Rio Branco, 38 - Centro

CEP. $175.00-090$ - Marília/SP 